\title{
Resonant Interaction of a Linear Array of Supersonic Rectangular Jets: An Experimental Study
}

Ganesh Raman

NYMA Inc.

Engineering Services Division

Brook Park, Ohio

and

Ray Taghavi

Department of Aerospace Engineering

University of Kansas

Lawrence, Kansas

November 1994

Prepared for

Lewis Research Center

Under Contract NAS3-27186

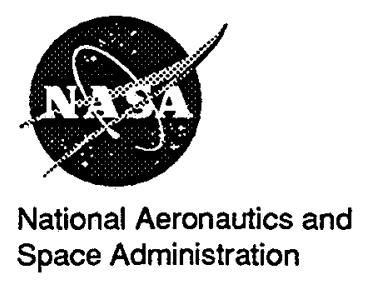




\title{
Resonant interaction of a linear array of supersonic rectangular jets: an experimental study
}

\author{
Ganesh Raman 1 \\ NYMA, Inc., Experimental Fluid Dynamics Section \\ Engineering Services Division \\ NASA Lewis Research Center Group \\ Brook Park, OH 44142 \\ Ray Taghavi ${ }^{2}$ \\ Department of Aerospace Engineering \\ University of Kansas \\ Lawrence, KS 66045
}

\begin{abstract}
This paper examines a supersonic multi-jet interaction problem that we believe is likely to be important for mixing enhancement and noise reduction in supersonic mixer-ejector nozzles. We demonstrate that it is possible to synchronize the screech instability of four rectangular jets by precisely adjusting the inter-jet spacing. Our experimental data agrees with a theory that assumes that the phase-locking of adjacent jets occurs through a coupling at the jet lip. Although the synchronization does not change the frequency of the screech tone, its amplitude is augmented by $10 \mathrm{~dB}$. The synchronized multi-jets exhibit higher spreading than the unsynchronized jets, with the single jet spreading the least. We compare the nearfield noise of the four jets with synchronized screech to the noise of the sum of four jets operated individually. Our noise measurements reveal that the more rapid mixing of the synchronized multi-jets causes the peak jet noise source to move upstream and to radiate noise at larger angles to the flow direction. Based on our results, we believe that screech synchronization is advantageous for noise reduction internal to a mixer-ejector nozzle,
\end{abstract}

since the noise can now be suppressed by a shorter acoustically lined ejector.

\section{Introduction}

1.1. Motivation for the present work

Enhanced mixing of supersonic rectangular jets is of current interest to the High Speed Research (HSR) community. Efforts are focused on meeting the noise requirements for the next-generation supersonic airplane. In order to meet the noise goal, researchers have suggested several types of mixer-ejector nozzle configurations. By enhancing the mixing and/or changing the directivity of its sound, we can considerably shorten ejector length and yet obtain the same noise suppression. While there is some engineering data on these mixer ejector nozzle configurations, there is not enough information on simpler configurations that could aid in the fundamental understanding of such flows. Morris (1990) emphasized the need for further experimental data on multiple supersonic jets including data on the modification of the growth rate of the jet mixing layer, mean flow contours in the merged jet region, and measurements of the entrained flow between the jets. The need for such data is crucial because there is neither a stability analysis, nor a

\footnotetext{
${ }^{1}$ Senior Research Engineer, Member AIAA

${ }^{2}$ Assistant Professor, Senior Member AIAA

Copyright $(\mathcal{C} 1995$ by the American Institute of Aeronautics and Astronautics, Inc. All rights reserved
} 
numerical simulation of multiple supersonic shockcontaining jets. Providing such information is one of our objectives.

The present work also studies the rectangular nozzle as an element of a lobed mixer ejector nozzle. We emphasize simple geometries that could be used internal to a shroud, which leads to a focus on the mixing and the near-field acoustics. More specifically, our aim is to study the flow and noise of multi-jets under conditions of screech synchronization. In addition, we document the single rectangular jet as the reference case. The present work demonstrates that it is possible to synchronize the flapping screech instability mode in a linear array of four jets, which yields enhanced mixing. The increased mixing rate of the jets moves the jet noise source upstream, providing a longer propagation length for an acoustic lining to reduce the internal mixing noise.

\subsection{Review of previous work}

Jets operated off design are known to produce an intense tone known as "jet screech." Screeching jets have now been studied by several researchers including Powell (1953), Lassiter and Hubbard (1954), and an excellent summary was provided by Tam (1991). It is now well recognized that the screech tone is created by growing coherent disturbances in the jet interacting with the shocks. The tone then propagates upstream (as feedback) to the jet exit and excites instabilities in the jet, thus closing the resonant loop. It is also well established that screeching jets have spread rates that are greater than their non-screeching counterparts. It is, therefore, attractive to use a natural excitation source such as jet screech, that requires no external, power for jet mixing enhancement and noise control.

Most published twin-jet work has focused on round jets. The acoustical properties, including the shielding effect of heated twin jets, were studied by Kantola (1981). The dynamic inter-nozzle pressure loads and resonance characteristics of a pair of circular jets were studied by Seiner et al (1988). The manner in which the resonant coupling depended on the inter-nozzle spacing was studied by Wlezien (1989). In addition, Morris (1990) presented calculations for the characteristics of instability waves in the initial mixing region of resonantly interacting twin circular supersonic jets.
There is, however, only limited data on a linear array of rectangular jets: Krothapalli et al. (1979); Chandrashekara et al. (1984). Moreover, to our knowledge there is no published data on the details of multiple rectangular jets with synchronized screech.

The noise of a supersonic shock-containing jet consists of tonal and non-tonal (broadband) components. The tonal components include the screech tone and its harmonics that are produced by a strong interaction between the advecting coherent structures and the standing shock waves. A weak interaction between the structures and the shocks produces broadband shock-associated noise. The relationship between shock associated broadband noise and screech tones was discussed by Tam et al. (1986).

Broadband noise encompasses all non-tonal noise including low frequency acoustic disturbances due to jet unsteadiness, jet mixing noise due to large-scale coherent structures in the jet, shock associated broadband noise produced by a weak interaction between the coherent structures and the shocks, and high frequency noise produced by fine scale turbulence. An impressive summary of jet mixing noise studies was provided by Lilley (1991). The connection between large- scale coherent structures and jet noise was addressed by Moore (1977), Crighton (1981), Mankbadi and Liu (1984), and Bridges and Hussain (1992); however, even today an understanding of the connection between the two is incomplete. In the present work, we attempt to document the tonal noise components from the multi-jets with synchronized screech. We compare the broadband components of noise from the synchronized multi-jets to that from the sum of the four jets run individually.

\subsection{Organization of the Paper}

We begin in section 2 with a detailed discussion of the supersonic multi-jet facility, measurement techniques, and a description of the strobed focusing schlieren system. In section 3 we discuss the screech instability of a single rectangular shock-containing jet using strobed schlieren records and measurements made using a pair of microphones on either side of the jet nozzle. In Section 4.1 we present theoretical arguments for the determination of the inter-jet spacing required for screech synchronization. In section 4.2 we provide 
verification of the theory for $\mathbf{M}_{\mathrm{j}}$ ranging from 1.3 to 1.8 , using measurements of relative phase in the nearfield of a single jet. Various possible mechanisms for screech synchronization are discussed, leading to the conclusion that phase-locking through mechanisms at the jet lip is most likely. In Section 4.3 we provide experimental proof of the synchronization of four supersonic rectangular jets. In Section 5 we provide mean flow data for synchronized and unsynchronized multiple supersonic rectangular jets. The entrained mass (indicated by the integrated mass-flux) of these jets is compared to that of single rectangular and circular jets. In Section 6 we document the near-field acoustic characteristics of the tonal and non-tonal (broadband) components. For the broadband components (jet mixing noise, shock associated, fine scale turbulence noise) we compare the noise of the four synchronized jets to that obtained by the sum of the four jets run independently. Finally, we conclude the paper with a discussion of the noise source location and directivity.

\section{Apparatus and Instrumentation 2.1. Jet Facility}

The experiments were carried out at the NASA Lewis Research Center Jet Facility. Figure 1 shows a schematic of the jet facility. The $76 \mathrm{~cm}$ diameter plenum tank was supplied with compressed air at pressures up to $875 \mathrm{kPa}(125 \mathrm{Psig})$ at $26.7^{\circ} \mathrm{C}\left(80^{\circ} \mathrm{F}\right)$. After passing through a filter that removed any dirt or dust, the air entered the plenum axially where it was laterally distributed by a perforated plate and a screen. Two circumferential splitter rings that contained acoustic treatment (kevlar) removed upstream valve noise. The flow was further conditioned by two 50 mesh screens before exiting into the room through the nozzles. The nozzle exit dimensions were $6.9 \times 34.5$ $\mathrm{mm}$, yielding an aspect ratio of 5 .

Figure 2 shows the multi-nozzle set-up. Each nozzle could be controlled independently using remotely controlled valves. The spacing between adjacent nozzles could be changed using the positioning apparatus shown in the schematic (Figure 2). An automatic feedback control system was used to maintain constant air supply conditions. The control system could restrict pressure variations during each run to within $0.2 \%$. Such precise control was essential for this experiment since the phase-locking between the four jets, which depended on the acoustic feedback from screech sources, was extremely sensitive to changes in operating conditions.

The nozzles, the probe traversing mechanism and other reflective surfaces in the nearfield were covered with two layers of acoustically absorbent open cell polyurethane foam $(0.635 \mathrm{~cm}$ thick uncompressed). The idea was to minimize strong refiections from the nozzles and plenum. The material is known to be very effective in absorbing incident sound in the frequency range from $1000-25,000 \mathrm{~Hz}$ (with several layers, lower frequencies can also be absorbed).

\subsection{Measurement Techniques}

Measurements were made using a pitot probe (o.d. of $0.8 \mathrm{~mm}$ ) that traversed the entire flowfield of the multi-jets. The probe was positioned by a three-dimensional traversing mechanism and controlled by computer. The pitot probe was connected to a pressure transducer by a Tygon tube $(0.8 \mathrm{~mm}$ i.d. $)$. Three different pressure tranducers, having a maximum range of $350 \mathrm{kPa}$ (50 Psig), $105 \mathrm{kPa}$ (15 Psig) and $35 \mathrm{kPa}$ (5 Psig), were used for the measurements. The centerline pressure at every axial station was used as a guide to select the transducer of an appropriate range for maximum sensitivity. The acoustic measurements were made using $(0.64 \mathrm{~cm}-1 / 4$ inch) dia. $\mathrm{B} \& \mathrm{~K}$ microphones mounted under each nozzle and on the threedimensional traversing mechanism for the nearfield noise surveys. The $\mathrm{B} \& \mathrm{~K}$ microphones were omnidirectional within $\pm 1 \mathrm{~dB}$ up to $10 \mathrm{kHz}$ and within $\pm 3 \mathrm{~dB}$ up to $20 \mathrm{kHz}$. The microphones were calibrated using a $\mathrm{B} \& \mathrm{~K}$ pistonphone calibrator, with corrections for day-to-day changes in atmospheric pressure. The sound pressure levels reported in this paper are in $\mathrm{dB}$ relative to $20 \mu \mathrm{Pa}$ (the threshold of human hearing).

For the microphone measurements outside the jet we were careful to avoid the very nearfield that is dominated by the potential field of the coherent hydrodynamic modes in the jet. The measurements made outside the jet are thus dominated by the acoustic field.

\subsection{Strobed Focusing Schlieren System}

A focusing schlieren system similar to Weinstein's 
(1993) was used for the flow visualization studies, providing a large field of view and the capability to focus anywhere in the flow. The strobed focusing schlieren system circuit modeled after Wlezien and Kibens's (1988) allowed viewing of the unsteady flapping motions of the jet. The system functions as follows. First, the camera's vertical synchronization signal is detected and delayed for 1.1 milliseconds, which corresponds to the start of the video information in the camera signal. Then, the delayed vertical synchronization signal and the start (positive zero crossing) of the next screech wave are synchronized. Then, this signal is synchronized with the control circuit's internal 5 microsecond system clock. The output of these synchronization steps serves as a countdown enable signal, starting the countdown device. Each time the countdown device runs, five microseconds are added to its previously input value. Upon reaching zero, the device fires the strobe light, increments the current delay, and clears the current countdown enable signal. The control circuit then waits for the next vertical synchronization signal from the camera. With this control circuit a "motion picture" of the screeching supersonic jet can be created. If it is necessary to freeze the flow, we can override the current delay counters.

\section{Instability of a Screeching Rectangular Jet}

Figure (3) shows schlieren photographs of the edge view (smaller dimension) of supersonic jets at various Mach numbers. These still photographs show the initial rarefaction (expansion) waves seen as edges of a black triangle at the jet exit in Figure 3(d-f) and their reflections that are compression waves (oblique shocks) seen as edges of the bright region. As the fully expanded jet Mach number increases, the shock spacing increases.

Figure (4) shows strobed focusing schlieren photographs of supersonic jets at various Mach numbers. The photographs were obtained by using the measured screech tone as a trigger with the circuit described earlier. The view in Figure (4) is again of the smaller dimension of the jet nozzle. The photos show the sinuous flapping instability mode of the jet. Details of the observed sinuous instability mode can be measured using hot-film probes located in the subsonic portions of the flow or using microphones located outside the jet. As shown in our earlier work (Raman and Rice (1994)) two hot-films (sensing $\mathbf{u}^{\prime}$ ) located on either side of the narrow dimension of the jet (in the subsonic region) will sense the $u^{\prime \prime}$ s to be $180^{\circ}$ out-of-phase. We also showed that the same result can be obtained using two microphones located at the jet exit (facing downstream) on either side of the narrow dimension of the nozzle. We use microphone measurements for phase referencing in the present work, and these are described in sections $3,4.2,4.3$, and 5.2 .

The screech frequency (which is a function of the shock spacing) was measured at the jet exit using a microphone. The screech Strouhal number, $\operatorname{St}\left(\mathrm{h}_{\mathrm{j}}\right)$, versus the fully expanded Mach number, $M_{j}$, is shown in Figure 5(a). As the jet's fully expanded Mach number increases, the Strouhal number of the screech tone decreases. This decrease is due to the increase in shock cell spacing with the Mach number (see Fig. 3(af)), which causes an increase in the screech wavelength (see Fig. 4(a-g)) and consequently a decrease in the screech frequency. The change in the fully expanded dimension, $h_{j}$, is small compared to the change in velocity $U_{j}$ with increase in $M_{j}$. Thus, as $M_{j}$ increases, $\mathrm{St}\left(\mathrm{h}_{\mathrm{j}}\right)$ decreases. The analytical solution of Tam (1988) is shown for comparison in Figure (5). Tam's theory incorporating a phase velocity, $\mathrm{c} / \mathrm{U}_{\mathrm{j}}=0.7$, is used here. Even though the frequency of the screech tone can be predicted very easily using simple relationships such as Tam's, no theory or numerical simulation can predict the amplitude of the screech tone. The measured values of screech tone amplitude versus the jet's fully expanded Mach number are shown in Figure 5(b). At low Mach numbers the shock structure of the jet is not strong enough to produce an intense tone. However, between $\mathrm{M}=1.3$ and 1.7 the screech tone's amplitude dominates other noise in the flow. Beyond $\mathrm{M}=1.8$ the shock spacing is too large to sustain the screech tone. Note that the phase of the screech tone measured using two microphones located on either side of the jet's narrow dimension indicates that the screech instability mode is anti-symmetric, over the entire Mach number range. This is in sharp contrast to the screech instability modes in a round jet (Seiner (1984)). In the round jet case, the screech mode undergoes significant changes with increase in $\mathrm{M}_{\mathrm{j}}$ (also known as staging of screech). 


\section{Spacing for Screech Synchronization}

\subsection{Theoretical Jet Spacing}

The theoretical spacing for synchronization can be determined by assuming that each jet is influenced only by its immediate neighbors. The effect of the screech tone from the other jets is assumed to be insignificant due to the shielding effect of the neighbor jet. It is also assumed that phase-locking of screech from adjacent jets occurs due to mechanisms effective at the lip. Note that even for a single jet, it is the receptivity at the jet lip that sustains screech, i.e., when the screech wave propagating upstream eventually reaches the nozzle lip, the pressure wave is scattered by the lip, creating a broad spectrum of wavelengths in the process (Morkovin (1969), Rogler and Reshotko (1975)). It is this broad spectrum that permits a coupling between the acoustic wave and hydrodynamic waves, thus producing a resonant loop. It is improbable that any other mechanism is responsible for the phase-locking, an assertion that will be proved towards the end of the next section. Assuming that the phaselocking occurs by a source-jet lip coupling, we can determine the theoretical jet spacing for screech synchronization if we know the location of the screech source. The location of the screech source is a function of the shock spacing, $\mathrm{L}_{\mathrm{s}}$, which was given by Tam (1988) as:

$$
L_{s}=2\left(M_{j}^{2}-1\right)^{1 / 2} h_{j}
$$

where $h_{j}$ and $M_{j}$ are the fully expanded jet dimension and Mach number respectively. We can determine $h_{j}$ using the simple geometric relationship given by Tam (1988), i.e.

$$
\frac{h_{j}}{h}=\left[\left(A_{j} / A_{d}\right)-1\right][b /(h+b)]+1
$$

where $h$ and $b$ represent the smaller and larger dimensions of the jet nozzle and $A_{d}$ and $A_{j}$ represent the area of the flow at the jet exit and the fully expanded jet cross-sectional area respectively. Note that $\left(A_{j} / A_{d}\right.$ ) is obtained assuming an isentropic expansion from the jet exit:

$$
\left(\frac{A_{j}}{A_{d}}\right)^{2}=\frac{M_{d}}{M_{j}^{2}}\left[\left(1+\frac{\gamma-1}{2} M_{j}^{2}\right) /\left(1+\frac{\gamma-1}{2} M_{d}^{2}\right)\right]^{(\gamma+1) /(\gamma-1)}
$$

Figure 6 shows a schematic of the multi-jet flow. Since the dominant screech sound source is known to be beyond the second shock, the distance, $q$, in Figure 6 from the jet exit to its own screech source (assumed to be $2.25 \mathrm{~L}_{\mathrm{s}}$ ) can be represented as:

$$
q=2.25 L_{s}=4.5\left(M_{j}^{2}-1\right)^{1 / 2} h_{j}
$$

For the jets to synchronize, the phase difference from the top of one jet to another should be zero. Consequently, the phase difference from the bottom of one jet to the top of another (i.e., from $\mathrm{s} 1$ to $\mathrm{s} 2$ in Figure $6)$ should be $180^{\circ}$. For this to happen the distances for the screech tone feedback to the jet exit plane, by paths $q$ and $r$, should differ by half the acoustic wavelength at the screech frequency. Replacing ' $r$ ' by $\left.\sqrt{(} q^{2}+s^{2}\right)$ the required relationship can be written as $\left.\sqrt{(} q^{2}+s^{2}\right)-q=\lambda / 2$. Thus, the inter-jet spacing, 's', can be determined from the above equation since the other quantities are known..

\subsection{Verification of Theory Using the Single Jet}

The formula for determining the minimum jet spacing for synchronized screech was verified by operating a single jet at Mach numbers of 1.3, 1.4, 1.5, 1.6, 1.7, and 1.8. The experimental data was obtained by locating one microphone at s1 (see Figure 6) and moving a second in the direction normal to the larger nozzle dimension (i.e., from $s 1$ to $s 2$ ). The stationary microphone represents the screech signal that propagated upstream (as feedback) by path $q$, whereas the second microphone measurement represents the signal obtained by a longer feedback path. A phase difference of $180^{\circ}$ is the spacing required for synchronized screech (i.e., microphones located at symmetric locations on two adjacent nozzles would sense a phase difference of zero). The phase difference for the various Mach numbers is plotted versus a dimensionless distance $(z / h)$ in Figure $7(a)$. Note that jets at a higher Mach number require a larger spacing for screech synchronization since the acoustic wavelength of screech increases with $M_{j}$. 
Figure 7(a) also shows the existence of a "null" region where the phase does not change. This "null" region is seen to increase with the fully expanded jet Mach number, $M_{j}$ (Fig. $7(b)$ ), and can be approximated by the curve fit: $1.61 \mathrm{M}_{\mathrm{j}}^{2}+3.1 \mathrm{M}_{\mathrm{j}}+1.29$. The ordinate of Fig. 7(b) is related to ' $h$ ' by a factor of 3.7. The existence of the "null" region and its growth with an increase in $\mathrm{M}_{\mathrm{j}}$ can be reconciled as follows. As $\mathrm{M}_{\mathrm{j}}$ increases, the sources of screech move downstream, and therefore the wavefronts arriving at the nozzle exit plane would be flatter in the near nozzle region as the $M_{j}$ increases. An added effect may contribute to this, because, not only do the screech sources move downstream, but the spacing between them increases as well.

Figure 8 shows the inter-jet spacing required for screech synchronization versus the fully expanded jet Mach number. The theoretical curve, which assumes that the screech source is located $2.25 \mathrm{~L}_{\mathrm{s}}$ downstream, is compared to the experimental data with the "null" region subtracted out. Table I illustrates that both measured and calculated values of $s / \lambda$ for screech synchronization are about 1.1 for $1.3<\mathrm{M}_{\mathrm{j}}<1.8$, where $0.235<\mathrm{St}\left(\mathrm{h}_{\mathrm{j}}\right)<0.103$, and $3.96<\lambda / \mathrm{h}<9.464$. The spacing where screech synchronization was obtained was so large $\left(\mathrm{s} / \mathrm{h}=8.16\right.$ at $\left.\mathrm{M}_{\mathrm{j}}=1.6\right)$ that the potential fields of neighboring jets could not possibly have influenced each other. In addition, the synchronization is very sensitive to changes in spacing ( $\mathrm{s} / \mathrm{h}$ )--an observation that excludes the potential field coupling as the possible cause of screech synchronization. It follows that in the absence of any other probable mechanism, phase-locking through mechanisms at the jet lip is most likely.

\subsection{Synchronization of Multiple Jet Screech}

Following the above experiments on a single jet, we conducted an experiment on four rectangular jets. The inter-nozzle spacing was very close $(\mathrm{s} / \mathrm{h}=8.16$, at $\mathrm{M}$ $=1.6$ ) to that determined by the theory and by the single jet experiments. However, there were slight differences. Figure 9 shows spectra measured at the exit of the four rectangular jets. The microphone was mounted under the nozzles with the sensing tip of the microphone located at the jet exit plane. The screech tone at a frequency of $\left.6784 \mathrm{~Hz}\left(\mathrm{St}_{\mathrm{j}} \mathrm{h}_{\mathrm{j}}\right)=0.128\right)$ stands almost $20 \mathrm{~dB}$ over the background level. Two harmon- ics of the screech tone $\left(\operatorname{St}\left(\mathrm{h}_{\mathrm{j}}\right)=0.256,0.384\right)$ are dominant and are also visible in the figure. The screech tone amplitudes from the four jets were 163.4, $161.9,159.1$, and $160.6 \mathrm{~dB}$. Although the average inter-jet spacing was $\mathrm{s} / \mathrm{h}=8.084$ (from nozzle edge-toedge), the inter-jet spacing was not exactly the same from jet-to-jet. The spacings were $\mathrm{s} / \mathrm{h}=8.037$ (between jets 1 and 2), 8.173 (between jets 2 and 3), and 8.041 (between jets 3 and 4). The phase difference between adjacent jets was obtained from the cross-spectral magnitudes (after 100 averages) between microphones located on the nozzles at the jet exit. The phase differences were $9.7^{\circ}$ (between jets 1 and 2), 9.1 (between jets 2 and 3 ) and $1.6^{\circ}$ (between jets 3 and 4 ). With a measurement accuracy of approximately \pm 5 , the jets could be considered synchronized. The coherence between signals measured at the exits of pairs of nozzles of the four nozzle assembly is shown in Figure 10. The coherence at $f$ and $2 f$ is almost 1 , indicating that the signals are highly correlated. The high levels of observed coherence lend credibility to the phase measurements reported here.

\section{Mean Flowfield of Synchronized and Unsynchronized Jets}

Since we wanted to study how synchronization affects the enhanced mixing of supersonic jets, we acquired mean flow data for three multi-jet operating conditions: (a) $\mathrm{M}=1.4, \mathrm{~s} / \mathrm{h}=5$; (b) $\mathrm{M}=1.6, \mathrm{~s} / \mathrm{h}=5$; (c) $\mathrm{M}=1.6$, $\mathrm{s} / \mathrm{h}=8$. Cases (a) and (b) have the same inter-jet spacing but different Mach numbers, whereas cases (b) and (c) have the same Mach number but different interjet spacings. For case (a), two out of four jets were synchronized, and the average screech amplitude measured at the jet lip was $159 \mathrm{~dB}$. In contrast, for case (b), none of the four jets was synchronized, and the average screech amplitude was $162.3 \mathrm{~dB}$. Finally, in case (c), all four jets were synchronized with an average screech amplitude of $161.25 \mathrm{~dB}$.

A pitot probe measurement was made on the yz plane at $X / D_{e}=7$ and 12 , where $D_{e}=4 A_{e} / \pi$ and where $A_{e}$ is the total exit area of the four jets. The extent of the measurements was from $y / D_{e}=-2.94$ to +2.94 and $\mathrm{z} / \mathrm{D}_{\mathrm{e}}=-5.4$ to +5.4 . The measurements included 1763 data points $(41 \times 43)$ with $\Delta y / D_{e}=0.0578$ and $\Delta z / D_{e}=$ 0.101 . The Mach number data shown in Figures 11 $\left(x / D_{e}=7\right)$ and $12\left(x / D_{e}=12\right)$ were obtained from the 
pitot tube data assuming that the local static pressure can be approximated by ambient pressure (a reasonable approximation for subsonic Mach numbers). The $x / D_{e}$ $=7,12$ stations were deliberately chosen to make the above calculation feasible. These stations are beyond the shock structures and supersonic regions of the jet.

From the surface plots of Figures 11 and 12, it appears that case (c) where all four jets are synchronized has the highest jet spread, indicated by the merging of the four jets. The second highest jet spread is that of case (a) where two out of four jets are synchronized. Case (b) with none of the four jets synchronized has the lowest jet spread.

The integrated mass-flux obtained from detailed flowfield data at several axial stations is shown in Figure (13). The normalized mass-flux was obtained using

$$
\frac{\dot{m}}{\dot{m}_{e}}=\frac{\iint(\rho u) d y d z}{\rho_{e} u_{e} A_{e}} .
$$

In addition to the cases described in Figs. 11, 12 (a-c), two other cases are shown for comparison in Figure 13: the single rectangular jet $\left(\mathrm{M}_{\mathrm{j}}=1.6\right)$ and the single circular jet $\left(\mathrm{M}_{\mathrm{j}}=1.63\right)$ from Zaman et al. (1994).

Trends displayed in Figure (13) warrant two comments. First, the visual trend observed in Figs. 11 and 12 (a-c) is confirmed and quantified, i.e., the case with all four jets synchronized has the highest entrained mass, followed by the case where two out of four jets are synchronized; the completely unsynchronized case has the least entrainment. Second, even the unsynchronized multi-jet case has a higher mass-flux than the single rectangular jet. Note that the circular jet data of Zaman et al. (1994) has the least entrainment. It was shown earlier (Zaman et al. (1994)) that circular supersonic jets entrain less than supersonic rectangular jets, an observation that will not be elaborated any further here.

\section{Nearfield-Noise Comparison}

\subsection{Screech and its Harmonics}

Figure 14 compares the screech tone measured at the nozzle lip of one of the jets under conditions of screech synchronization to that obtained from a single rectangular jet. The synchronization does not change the frequency of the screech tone significantly. However, the amplitude of the screech tone is augmented by about $10 \mathrm{~dB}$. This augmentation is believed to be due to the resonant phase-locking between the screeching jets. Note that the noise at all frequencies ranging from $0-25,600 \mathrm{~Hz}\left(\mathrm{St}\left(\mathrm{h}_{\mathrm{j}}\right)=0-0.48\right)$ is higher for the multi-jet, screech-synchronized case as compared to the single rectangular jet.

Figure $15(a, b)$ shows nearfield noise contours for the screech tone and its harmonic for the four jets operated at $\mathrm{M}=1.6$ under conditions of screech synchronization $(\mathrm{s} / \mathrm{h}=8)$. The complicated near-field noise map for the fundamental screech tone $\left(\mathrm{St}\left(\mathrm{h}_{\mathrm{j}}\right)=0.128\right)$ reveals regions of screech cancellation and reinforcement. It is known that the screech noise is produced by discrete coherent multiple sources (Powell(1953)). The screech noise from these sources can undergo reflections from the interface between the subsonic and supersonic flow in the jet or can refract as it emanates through the shear layer. The result of these phenomena in the four jets interacting resonantly produces a map of well defined regions of screech reinforcement and cancellation. These regions are seen as islands of high amplitude (reinforcement) or low amplitude (cancellation). The very nearfield of a single rectangular jet was studied previously by Rice and Taghavi (1992). They observed very strong interference regions in the downstream and sideline (y) directions, which is not surprising since the screech tone propagates predominantly in the upstream direction. For the harmonic of the screech tone $\left(\mathrm{St}\left(\mathrm{h}_{\mathrm{j}}\right)=0.256\right)$, the sound pressure patterns are not as complex as for the fundamental screech tone. The sound radiation direction for the harmonic that can be inferred from Figure 15 (b) is normal to the flow direction, thus agreeing with the results of Powell (1953).

Our previous work (Raman and Rice (1994)) showed that for a rectangular jet the hydrodynamic instability mode at the screech frequency occurred in the antisymmetric (sinuous) mode, about the smaller dimension of the jet, whereas its harmonic was symmetric (varicose) over the same region. In addition, we also observed that the radiated screech noise was out- 
of-phase on either side of the small jet dimension, whereas its harmonic was in-phase over the same region. Similar observations were made for the jets used in the present work but they will not be discussed any further here.

\subsection{Broadband components}

Figure 16(a,b) shows the spectral (third-octave band) evolution for multiple jets with synchronized screech both along the major and minor axes directions. We have focused on the broadband noise contained in the four bands most important to this experiment. The bands were centered on $\operatorname{St}\left(\mathrm{h}_{\mathrm{j}}\right)=0.0149$ (low frequency noise), 0.075 (jet mixing noise), 0.189 (shock associated broadband noise), and 0.3024 (high frequency broadband noise). The lower and upper $\mathrm{St}\left(\mathrm{h}_{\mathrm{j}}\right)$ bandlimits for the four bands were $(0.0133-0.0167)$, (0.066 - 0.084), (0.168 - 0.212), and (0.267 - 0.336) respectively.

It is of interest here to study the noise produced by the multi-jet interaction. To do this we measured the noise in the $\mathrm{xy}$ and $\mathrm{xz}$ planes for the screech synchronized case as well as the case when the four jets were operated individually. The $x y$ plane $(\mathrm{z} / \mathrm{h}=0)$ was located midway between jets 2 and 3 (see Fig. 2). The $\mathrm{xz}$ plane $(\mathrm{y} / \mathrm{h}=0)$ was located above the four jets. For the xy plane, we took two sets of measurements by operating the top two jets (jets 1 and 2 of Figure(2)) individually. The noise levels were summed, and $3 \mathrm{~dB}$ was added for the contribution of the bottom two jets. For the $\mathrm{xz}$ plane, four sets of measurements were made by running each jet individually; then the noise levels were summed.

The discussion will focus on the differences between running the jets simultaneously under conditions of screech synchronization and running each jet individually and summing the noise contributions. The sound pressure levels (SPL(dB)) were calculated using $\mathrm{SPL}(\mathrm{dB})=10 \log \left(\mathrm{p} / \mathrm{p}_{\mathrm{re}}\right)^{2}$, where $\mathrm{p}$ is the rms sound pressure and $\mathrm{p}_{\mathrm{re}}$ is the reference rms sound pressure $(20 \mu \mathrm{Pa})$. The mean square values of the sound pressure from the four jets operated individually were combined algebraically, assuming that the non-tonal sound sources have a random phase relationship.

$$
\text { Hence } \frac{p_{1}^{2}+p_{2}^{2}+p_{3}^{2}+p_{4}^{4}}{p_{r e}^{2}}=\sum_{i=1}^{4} \operatorname{antilog}\left(\frac{S P L_{i}}{10}\right)
$$

After algebraic manipulation the total sound pressure level (SPL) can be represented as $\mathrm{SPL}_{t}(\mathrm{~dB})=10$ $\log \left(\sum_{\mathrm{i}=1}^{4} 10^{\mathrm{SPL} i / 10}\right)$. Note that such a summation is not valid for screech tones since the sources do not have a random phase relationship and cancellation or reinforcement of sound levels could result. The four bands defined earlier are represented by Figures 17-20. Parts (a) and (c) represent the $x y$ and $x z$ planes for the multijet synchronized screech case, whereas parts (b) and (d) represent the same planes for the sum of jets run individually. For brevity the screech synchronized multi-jet case and the sum of four jets run individually case will be referred to as case I and case II respectively. The nearfield noise results are summarized in Table II.

The peak low frequency noise in the xy plane is higher by $6 \mathrm{~dB}$ for case I than for case II (see Fig. 17(a,b)). In contrast, the low frequency noise in the $x z$ plane does not show an appreciable difference between the two cases (Fig. 17(c,d)). In addition, no appreciable difference in directivity is noted between cases I and II in both the $x y$ and $x z$ planes for this spectral band.

The jet mixing noise (Fig. 18(a-d)) which is of prime concern, is higher for case I than for case II by $7.6 \mathrm{~dB}$ in the xy plane. However, the peak jet noise source is moved upstream by $2 \mathrm{D}_{\mathrm{e}}$ for case I as compared to case II. On the $\mathrm{xz}$ plane case I is actually quieter than case II by $2.3 \mathrm{~dB}$ : an observation that could be due to shielding in the direction in which the jets are stacked. Here, let us note that for a single jet at $\mathrm{M}_{\mathrm{j}}=1.6\left(\mathrm{M}_{\mathrm{c}}=\right.$ 1.12 assuming $\mathrm{c} / \mathrm{U}_{\mathrm{j}}=0.7$ ) the dominant direction of noise radiation as described by Ffowcs Williams (1963) for an ideally expanded supersonic jet is $\theta=\arccos \left(1 / M_{c}\right)=$ $28^{\circ}$. The present case is more complicated due to the presence of shocks and screech. Cases I and II are seen to radiate noise at larger angles to the flow. For the jet mixing noise the directivity angles (measured from the flow direction) of the dominant lobes are $50^{\circ}$ and $42^{\circ}$ for cases $I$ and $I I$ respectively in the xy plane and $60^{\circ}$ and $40^{\circ}$ for cases I and II respectively in the $\mathrm{xz}$ 
plane. Let us recall here that of the various noise components, the jet mixing noise is most important since it has a downstream directivity and is therefore the most difficult to attenuate. The upstream shift in the peak jet noise source and the larger directivity angles caused by the resonant jet interaction are advantageous for noise reduction since the noise could now be suppressed by an acoustically lined ejector of a shorter length.

The shock-associated broadband noise (Figure 19(a-d)) shows some very interesting characteristics. The peak noise levels are 142 and $138 \mathrm{~dB}$ for cases $I$ and II in the xy plane with no appreciable change in the location of the apparent source. In the xy plane both cases display a dual-lobe. The downstream directed lobe has a directivity angle of $60^{\circ}$ to the flow direction. In contrast, the upstream propagating lobe is directed at $125^{\circ}$ to the flow direction for case I and $115^{\circ}$ for case II. The peak noise levels in the $\mathrm{xz}$ plane are 147 and $149 \mathrm{~dB}$ for cases I and II respectively. There is an upstream shift in the apparent source for case I on the $\mathrm{xz}$ plane by $2 \mathrm{D}_{\mathrm{e}}$. The directivity of the primary noise lobe in the $\mathrm{xz}$ plane is the same for both cases. However, case II exhibits a secondary lobe directed in the downstream direction. Such a secondary lobe is nonexistent for case I.

Figure 20(a-d) shows similar data for the high frequency noise band. In the $x y$ plane, case $I$ is noisier (higher peak noise) by $1 \mathrm{~dB}$ than case II with a $0.5 \mathrm{D}_{\mathrm{e}}$ upstream shift in the apparent source location, and no appreciable change in the directivity angle. On the $\mathrm{xz}$ plane, case $I$ is quieter by $5 \mathrm{~dB}$ than case II. The apparent source for case $\mathrm{I}$ is $1.5 \mathrm{D}_{\mathrm{e}}$ upstream of that for case II and again there is no appreciable change in the directivity angle.

Figure 21 (a-c) shows the fall-off of the acoustic field along the direction of noise radiation in the $x z$ plane for the three acoustic components of noise (i.e., jet mixing noise, shock-associated broadband noise, and high frequency jet noise). Data is shown for the screech synchronized multi-jet case (case I) and the sum of four jets run individually case (case II). The fall-off curve is generated by taking data along the dominant directivity lobe angle, starting from the true peak noise location. Ahuja et al. (1987) showed that if the true source location and directivity angle are accounted for, then the inverse square law will reasonably predict the nearfield noise. The directivity is accounted for by taking data along the dominant propagation direction as described above (Note that data taken in directions other than the dominant propagation direction will not exhibit the inverse square law behavior). The inverse square law curve adjusted for the true source location is compared to the measured data for case $I$. The agreement between the data and the inverse square law is satisfactory indicating that our acoustic data is not severely contaminated by the hydrodynamic field of the jet.

\section{Concluding Remarks}

We have examined some of the flow and acoustic features of multiple supersonic rectangular jets with phase-locked screech. The primary motivation for this work was provided by the expectation that multi-jets with synchronized screech could provide significant mixing and noise benefits. The secondary motivation was the lack of available information on the aeroacoustics of simple multi-element jet flows. Our experimental data agreed with a theory assuming that the phase-locking occurred because of a screech source-jet lip interaction between neighboring jets.

We observed that the jets with synchronized screech had a higher spread rate and integral mass flux than the unsynchronized multi-jets. The single rectangular jet had the least spread rate and mass flux. Under conditions of screech synchronization, the frequency of the screech tone remained the same as that of a single jet run under the same conditions. However, the amplitude of the screech tone was augmented by $10 \mathrm{~dB}$ at the jet lip due to the resonant interaction. The nearfield noise data from the multi-jets with synchronized screech was compared to that obtained from adding the noise from each jet run separately. For the two cases mentioned above, we documented the directivity angle, apparent source location, and apparent peak source amplitude. Although the resonant mixing produces more noise in the xy plane, the noise source moves upstream.

This novel experimental study has achieved our defined goals. We have demonstrated that it is possible to operate four supersonic shock containing jets with 
phase-locked screech and produce both mixing and noise benefits. Finally, we believe that the data is of significant scientific and engineering value in the quest to understand and control multiple, complex supersonic shock containing jet flows.

\section{Acknowledgements}

The work described in this paper was carried out at the NASA Lewis Research Center, Cleveland $\mathrm{OH}$. The authors are grateful to Dr. C.K.W. Tam, Dr. E.J. Rice, Dr. J. Bridges, and Dr. E. Envia for their technical input. Dr. R. Ziegfeld provided comments that improved the presentation.

\section{REFERENCES}

Ahuja, K.K., Tester, B.J. \& Tanna, H.K. 1987 Calculation of far field jet noise spectra from near field measurements with true source location. J. Sound Vib. $116,415-426$.

Bridges, J. \& Hussain, F. 1992 Direct evaluation of aeroacoustic theory in a jet. J. Fluid Mech. 240, 469501.

Chandrashekara, M.S., Krothapalli, A. \& Baganoff, D. 1984 Mixing characteristics of an underexpanded multiple jet ejector. JIAA TR-55, Stanford Univ. Rep., Dept. of Aero. \& Astro.

Crighton, D.G. 1981 Acoustics as a branch of fluid mechanics. J. Fluid Mech. 106, 261-298.

Ffowcs Williams, J.E. 1963 The noise from turbulence convected at high speed. Phil Trans. Roy. Soc. (London) A 255, 469-503.

Kantola, R.A. 1981 Acoustic properties of heated twin jets. J. Sound Vib. 79, 79-106.

Krothapalli, A., Baganoff, D. \& Karamcheti, K. 1979 An experimental study of multiple jet mixing. JIAA TR-23, Stanford Univ. Rep., Dept. of Aero. \& Astro.

Lassiter, Leslie W. \& Hubbard, Harvey H. 1956 The near noise field of static jets and some model studies of devices for noise reduction. NACA Rep. 1261.

Lilley, G.M. 1991 Jet noise classical theory and experiments. aeroacoustics of flight vehicles, theory and practice, Vol. 1: noise sources, NASA RP-1258, WRDC, TR-90-3052, H.H. Hubbard, Ed., 211-289.

Mankbadi, R.R. \& Liu, J.T.C. 1984 Sound generated aerodynamically revisited: large-scale structures in a turbulent jet as a source of sound. Phil. Trans. R.
Soc. Lond. A 311, 183.

Moore, C.J. 1977 The role of shear-layer instability waves in jet exhaust noise. J. Fluid Mech. 80, 321-367. Morkovin, M.V. 1969 Critical evaluation of transition from laminar to turbulent shear layers with emphasis on hypersonically travelling bodies. AFFDL-TR-68149.

Morris, P.J. 1990 Instability waves in twin supersonic jets. J. Fluid Mech. 220, 293-307.

Powell, A. 1953 On the noise emanating from a two dimensional jet above the critical pressure. Aeronautical Quarterly 4, 103-122.

Raman, G. \& Rice, E.J. 1994 Instability modes excited by natural screech tones in a supersonic rectangular jet. Phys. Fluids 6, (to appear).

Rice, E.J. \& Taghavi, R. 1992 Screech noise source structure of a supersonic rectangular jet. AlAA paper 92-0503.

Rogler, H.L. \& Reshotko, E. 1975 Disturbances in a boundary layer introduced by a low intensity array of vortices, SIAM. J. Appl. Math 28, 431-462.

Seiner, J.M. 1984 Advances in high speed jet aeroacoustics. AlAA paper 84-2275.

Seiner, J.M., Manning, J.C. \& Ponton, M.K. 1988 Dynamic pressure loads associated with twin supersonic plume resonance. AIAA J. 26, 954-960.

Tam, C.K.W. 1991 Jet noise generated by largescale coherent motion. aeroacoustics of flight vehicles: theory and practice, Vol. 1: noise sources, NASA RP. 1258, WRDC, TR-90-3052, H.H. Hubbard, Ed., 311390.

Tam, C.K.W. 1988 The shock-cell structures and screech tone frequencies of rectangular and nonaxisymmetric supersonic jets. J. Sound Vib. 121, 135147.

Tam, C.K.W., Seiner, J.M. \& Yu, J.C. 1986 Proposed relationship between broadband shock associated noise and screech tones. J. Sound Vib. 110, 309-321.

Weinstein, L.M. 1993 Large-field high-brightness focusing Schlieren system, AIAA J. 31, 1250-1255.

Wlezien, R.W. 1989 Nozzle geometry effects on supersonic jet interaction. AIAA J. 27, 1361-1367.

Wlezien, R.W. \& Kibens, V. 1988 Influence of nozzle asymmetry on supersonic jets. AIAA J. 26, 2733. Also AIAA 86-0277, MDRL 86-2.

Zaman, K.B.M.Q., Reeder, M.F. \& Samimy, M. 1994 Control of an axisymmetric jet using vortex generators. Phys. Fluids 6, 778-793. 
TABLE I

Jet spacing for screech synchronization

\begin{tabular}{|c|c|c|c|c|c|c|c|c||}
\hline $\mathrm{M}_{\mathrm{j}}$ & $\left(\mathrm{h}_{\mathrm{j}} / \mathrm{h}\right)$ & $\mathrm{f}$ & $\mathrm{St}\left(\mathrm{h}_{\mathrm{j}}\right)$ & $\lambda / \mathrm{h}$ & $\begin{array}{c}\mathrm{s} / \mathrm{h} \\
\text { theory }\end{array}$ & $\begin{array}{c}\mathrm{s} / \mathrm{h} \\
\text { expt. }\end{array}$ & $\begin{array}{c}\mathrm{s} / \lambda \\
\text { theory }\end{array}$ & $\begin{array}{c}\mathrm{s} / \lambda \\
\text { expt. }\end{array}$ \\
\hline 1.3 & 1.054 & 12,768 & 0.235 & 3.96 & 4.422 & 4.15 & 1.116 & 1.048 \\
\hline 1.4 & 1.096 & 10,208 & 0.186 & 4.95 & 5.488 & 5.16 & 1.109 & 1.042 \\
\hline 1.5 & 1.146 & 8,576 & 0.155 & 5.89 & 6.537 & 6.43 & 1.1098 & 1.091 \\
\hline 1.6 & 1.171 & 6,784 & 0.120 & 7.455 & 7.933 & 8.32 & 1.064 & 1.11 \\
\hline 1.7 & 1.281 & 6,112 & 0.114 & 8.275 & 9.092 & 9.17 & 1.098 & 1.108 \\
\hline 1.8 & 1.366 & 5,344 & 0.103 & 9.464 & 10.46 & 10.27 & 1.1052 & 1.085 \\
\hline
\end{tabular}

TABLE II

Summary of nearfield noise results

\begin{tabular}{||c|c|c|c|c|}
\hline Noise component & $\begin{array}{c}\text { Measurement } \\
\text { plane }\end{array}$ & $\begin{array}{c}\text { Peak noise level } \\
(\mathrm{dB})\end{array}$ & $\begin{array}{c}\text { Source location } \\
\left(\mathrm{x} / \mathrm{D}_{\mathrm{e}}\right)\end{array}$ & $\begin{array}{c}\text { Directivity in the } \\
\text { measurement } \\
\text { plane }\end{array}$ \\
\hline \multirow{2}{*}{ Low frequency } & $\mathrm{xy}$ & $148(142)$ & - & - \\
\cline { 2 - 5 } & $\mathrm{xz}$ & $150.7(150.7)$ & - & - \\
\hline \multirow{2}{*}{ Jet mixing noise } & $\mathrm{xy}$ & $140(139)$ & $6(8)$ & $50^{\circ}\left(42^{\circ}\right)$ \\
\cline { 2 - 5 } & $\mathrm{xz}$ & $148(151)$ & $6.5(6.5)$ & $60^{\circ}\left(40^{\circ}\right)$ \\
\hline \multirow{2}{*}{$\begin{array}{c}\text { Shock associated } \\
\text { broadband noise }\end{array}$} & $\mathrm{xy}$ & $142(138)$ & $2(2)$ & $60^{\circ}\left(60^{\circ}\right), 125^{\circ}$ \\
\cline { 2 - 5 } & $\mathrm{xz}$ & $147(149)$ & $4(6)$ & $\left.115^{\circ}\right)$ \\
\hline \multirow{2}{*}{$\begin{array}{c}\text { High frequency } \\
\text { noise }\end{array}$} & $\mathrm{xy}$ & $142(141)$ & $3.5(4)$ & $105^{\circ}\left(100^{\circ}\right)$ \\
\cline { 2 - 5 } & $\mathrm{xz}$ & $141(146)$ & $3.5(5)$ & $95^{\circ}\left(90^{\circ}\right)$ \\
\hline
\end{tabular}

Note that the numbers in the table are for multiple jets with screech synchronized (case I). The corresponding data for the sum of four jets run independently (case II) are given in parentheses. 


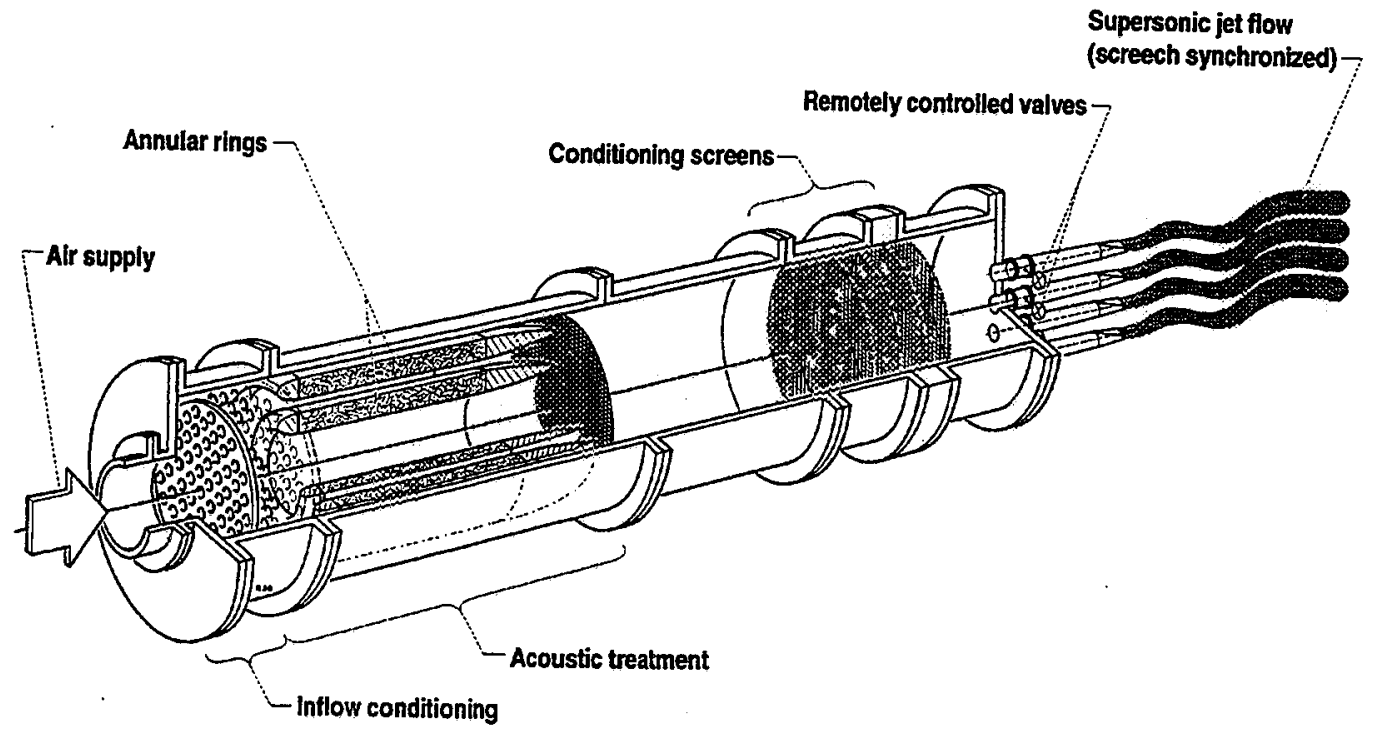

Figure 1.-Schematic of supersonic jet facility.

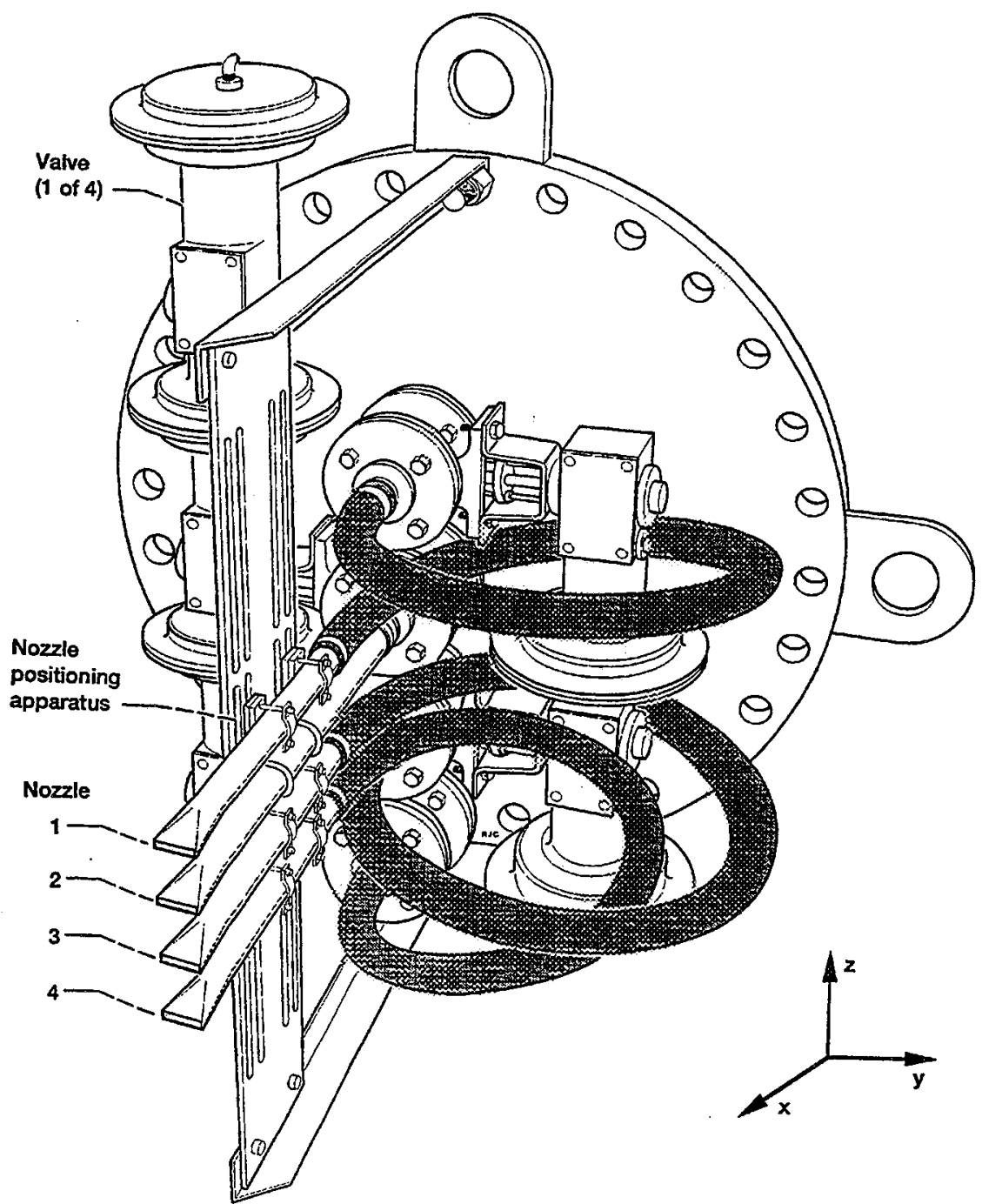

Figure 2.-Multi-nozzle experimental apparatus. 


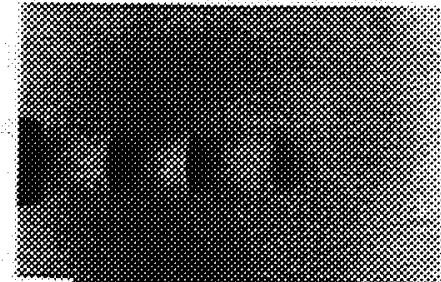

3

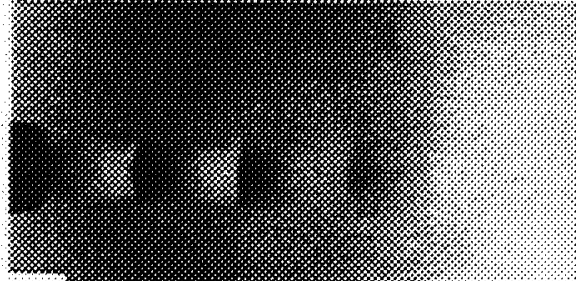

3

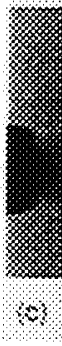

s.

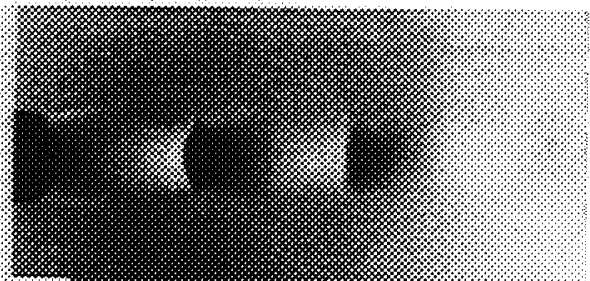

3

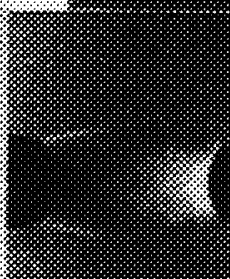

z"s

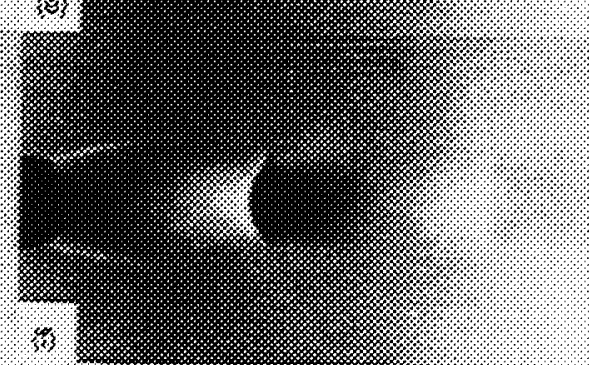

Figure 3.-Focusing Schlieren photographs of the shock-cell structure of underexpanded rectangular jets. $M_{j}=$ (a) 1.2, (b) 1.3, (c) 1.4, (d) 1.5, (e) 1.6, (f) 1.7 .

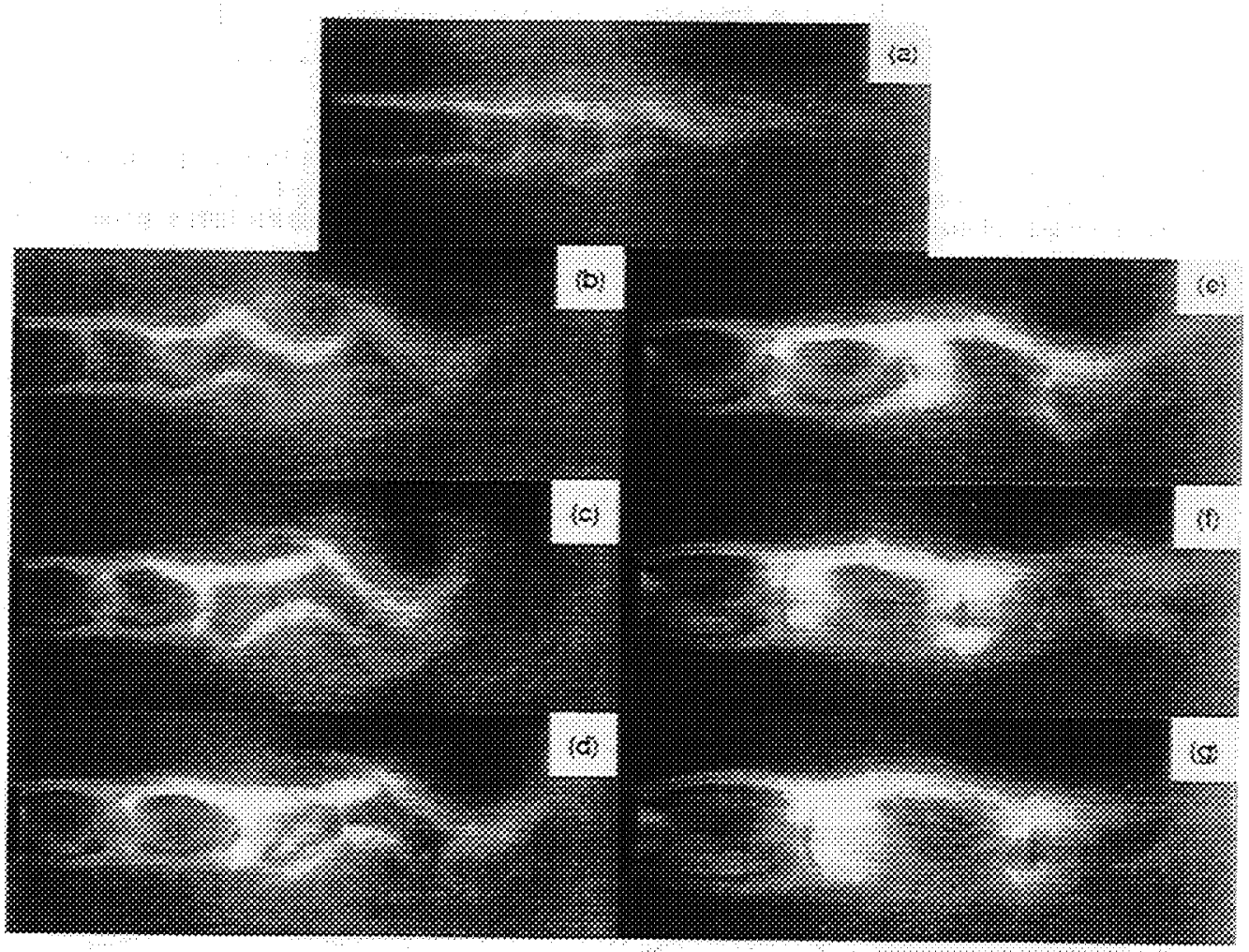

Figure 4.-Strobed Schlieren photographs of underexpanded rectangular jets. $M_{j}=$ (a) 1.1, (b) 1.2 , (c) 1.3, (d) 1.4, (e) 1.5, (f) 1.6, (g) 1.7. 

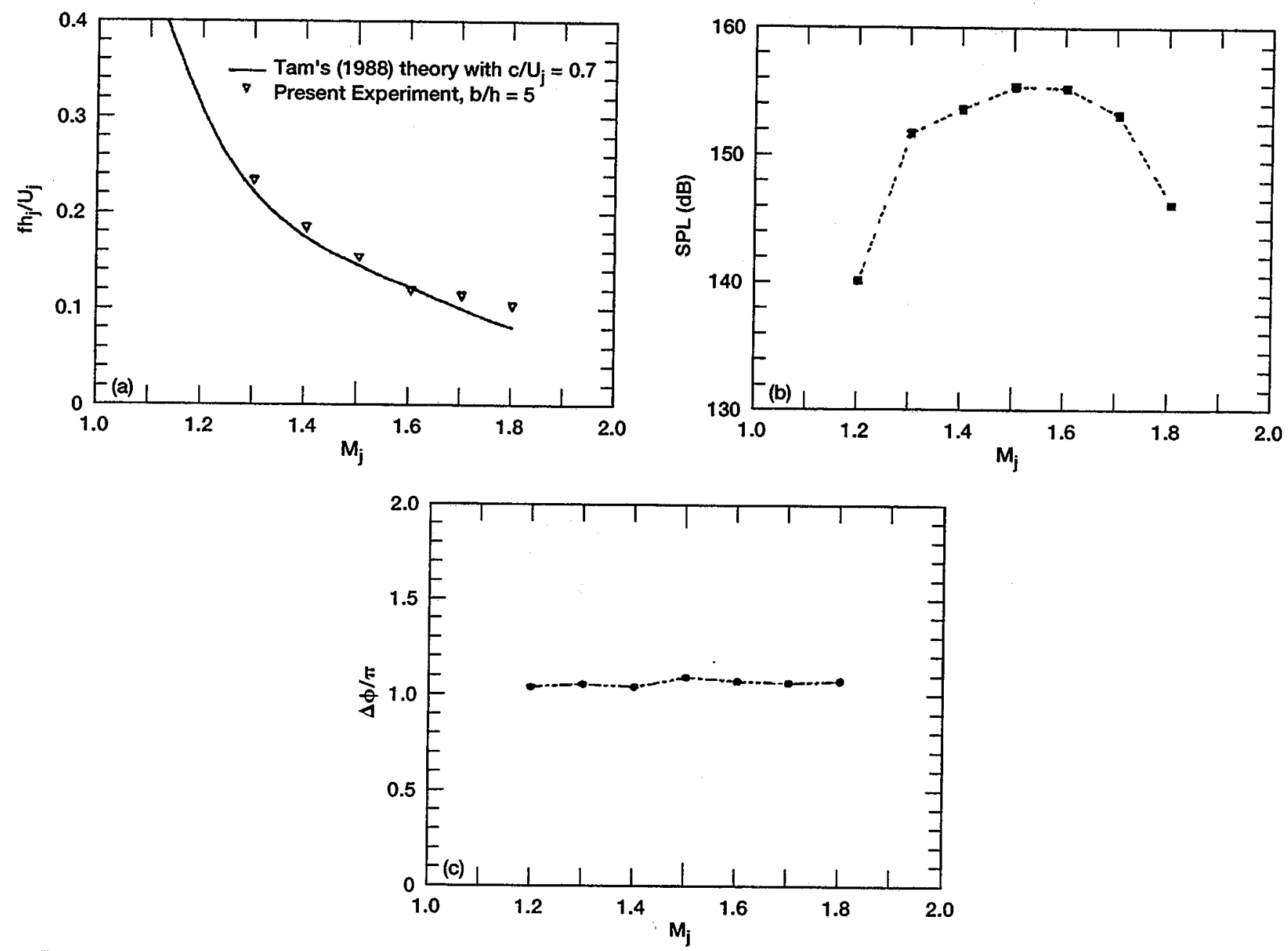

Figure 5.-Screech tone characteristics of a single rectangular jet. (a) Screech Strouhal number versus the fully expanded Mach number. (b) Screech sound pressure level at the nozzle lip versus the fully expanded Mach number. (c) Phase difference at the screech frequency between microphones located on either side of the nozzle exit versus the fully expanded Mach number.

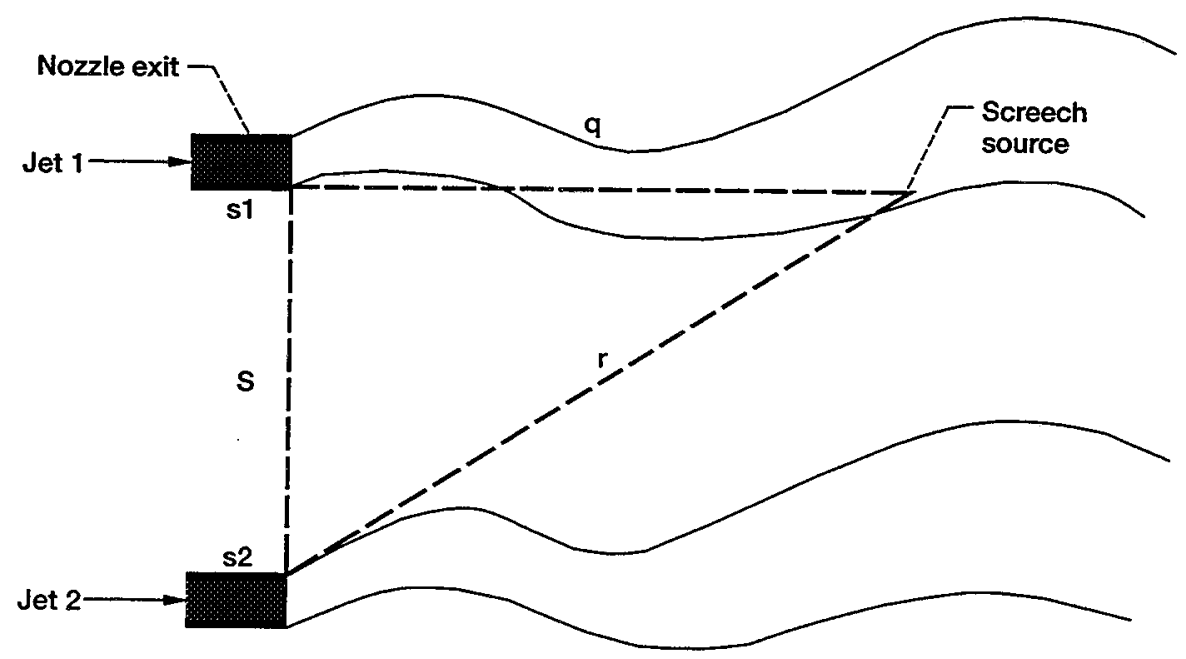

Figure 6. Schematic of jet spacing required for screech synchronization. 

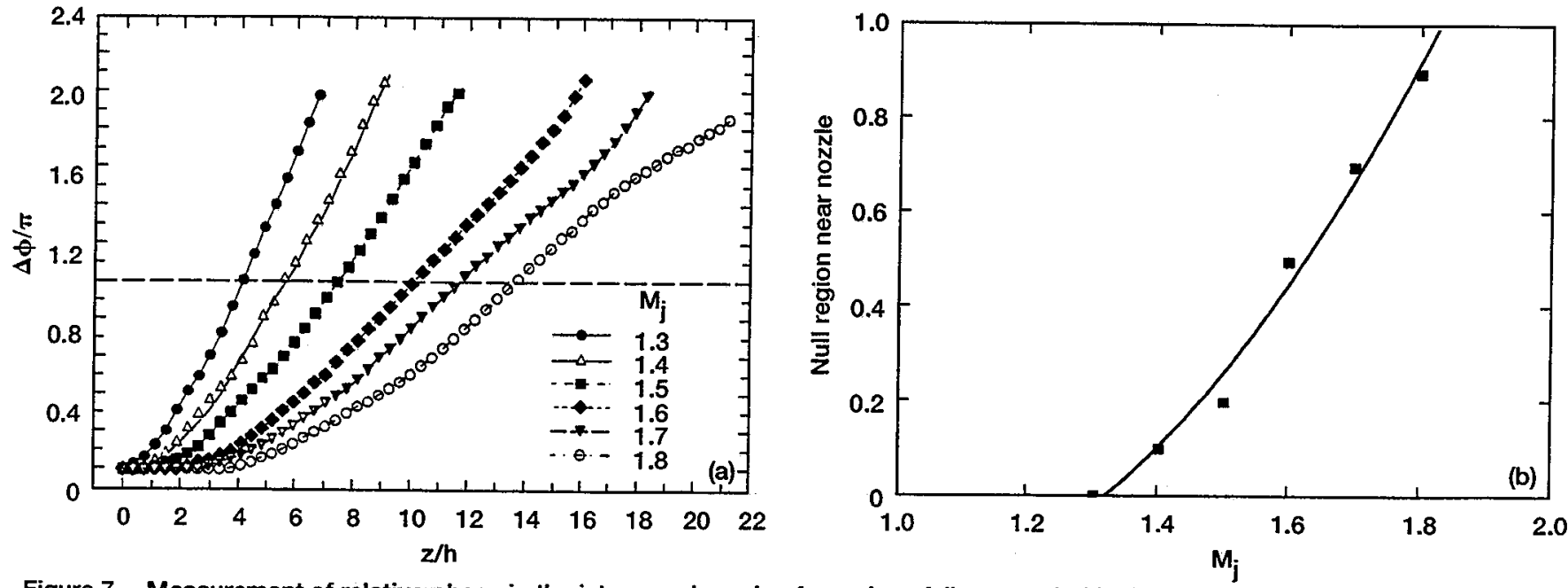

Figure 7.-Measurement of relative phase in the inter-nozzle region for various fully expanded jet Mach numbers. (a) Phase variation versus $z / h$ ( $z$ is perpendicular to the larger nozzle dimension). (b) Variation of the "null region" with the fully expanded Mach number.

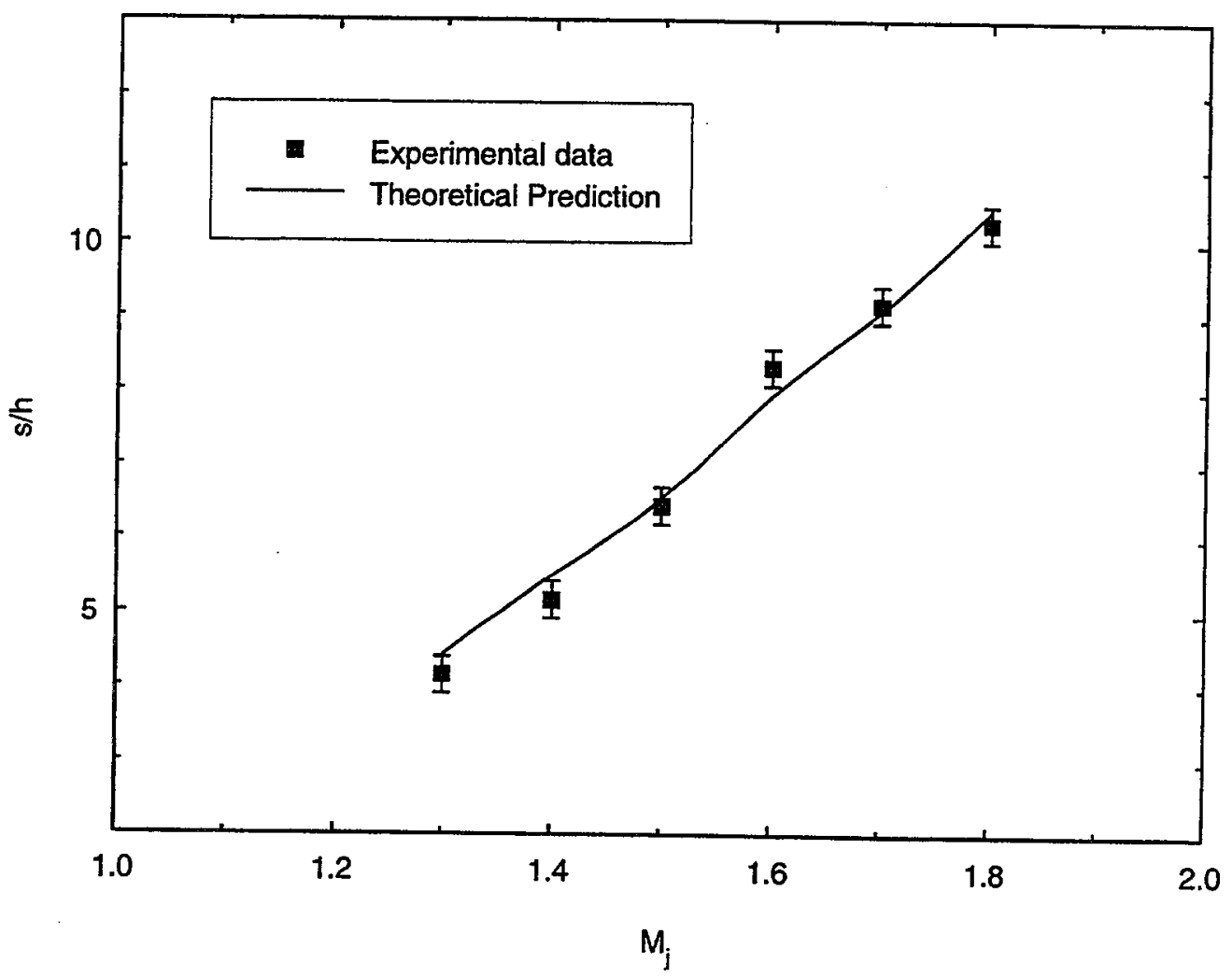

Figure 8.-Comparison of experimental and theoretical nozzle spacing required for screech synchronization. 

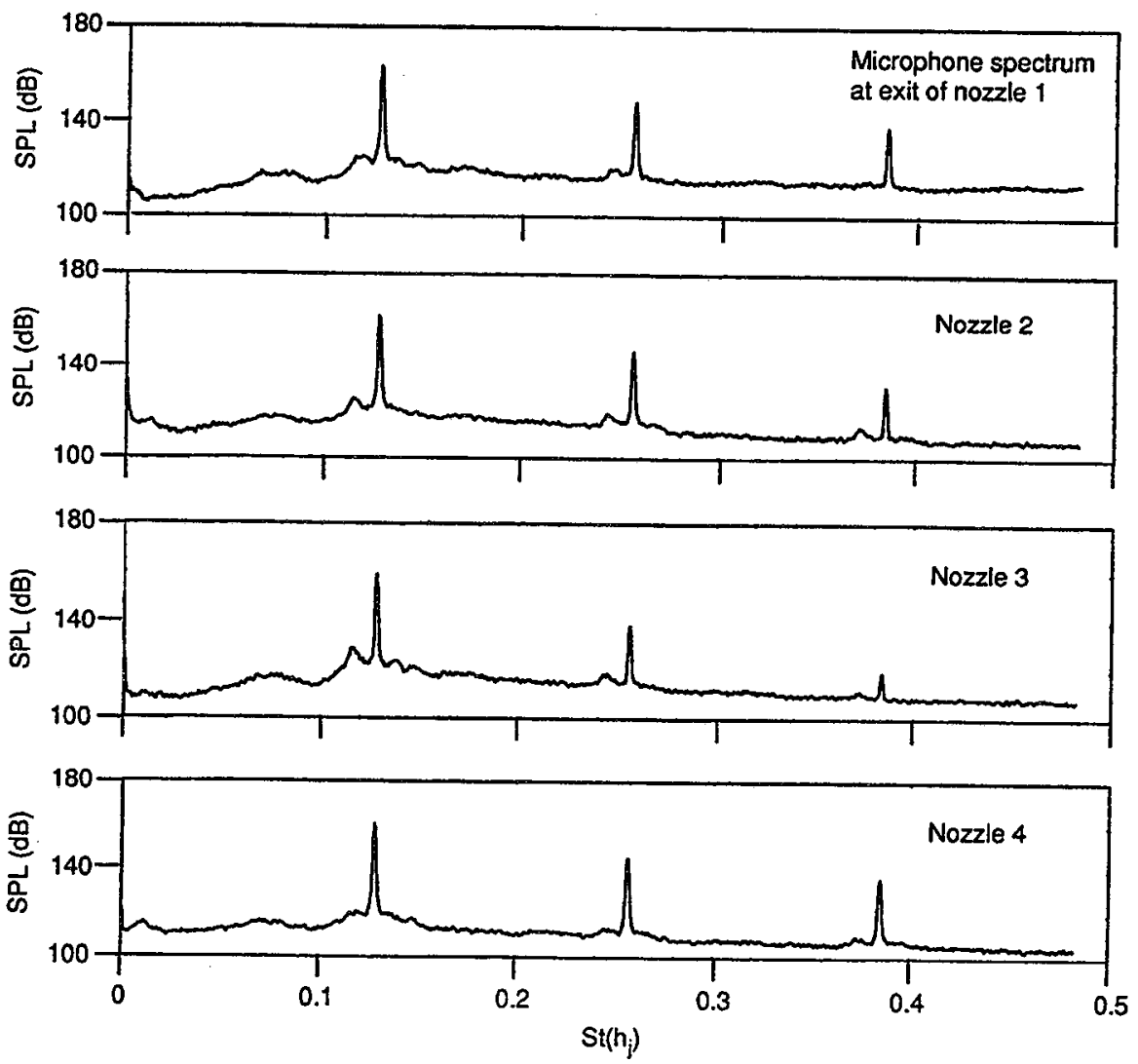

Figure 9.-Sound pressure level spectra measured at the exit of the four jet nozzles.
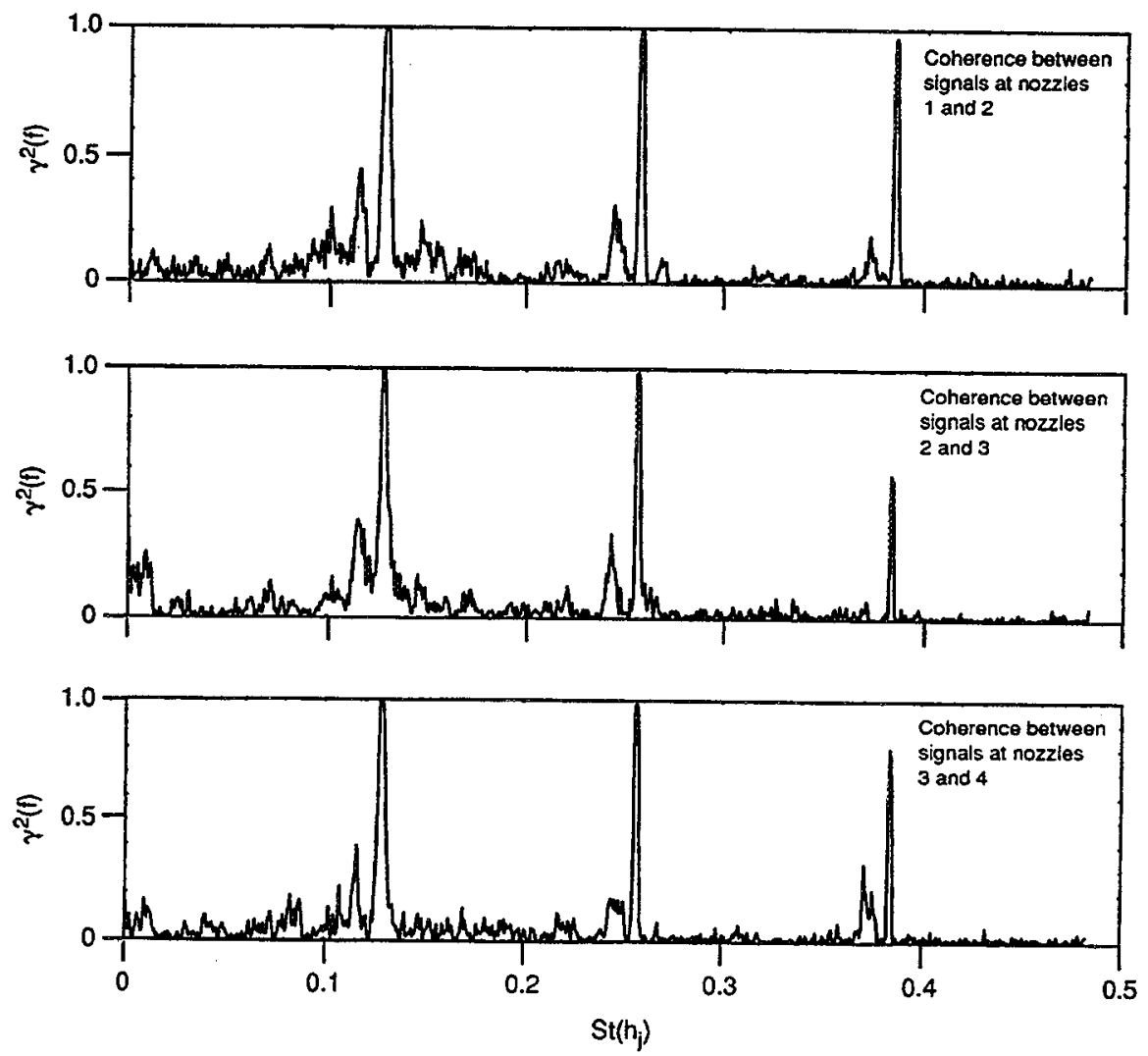

Figure 10.- Linear spectral coherence between pairs of jets measured at the jet exit plane. 

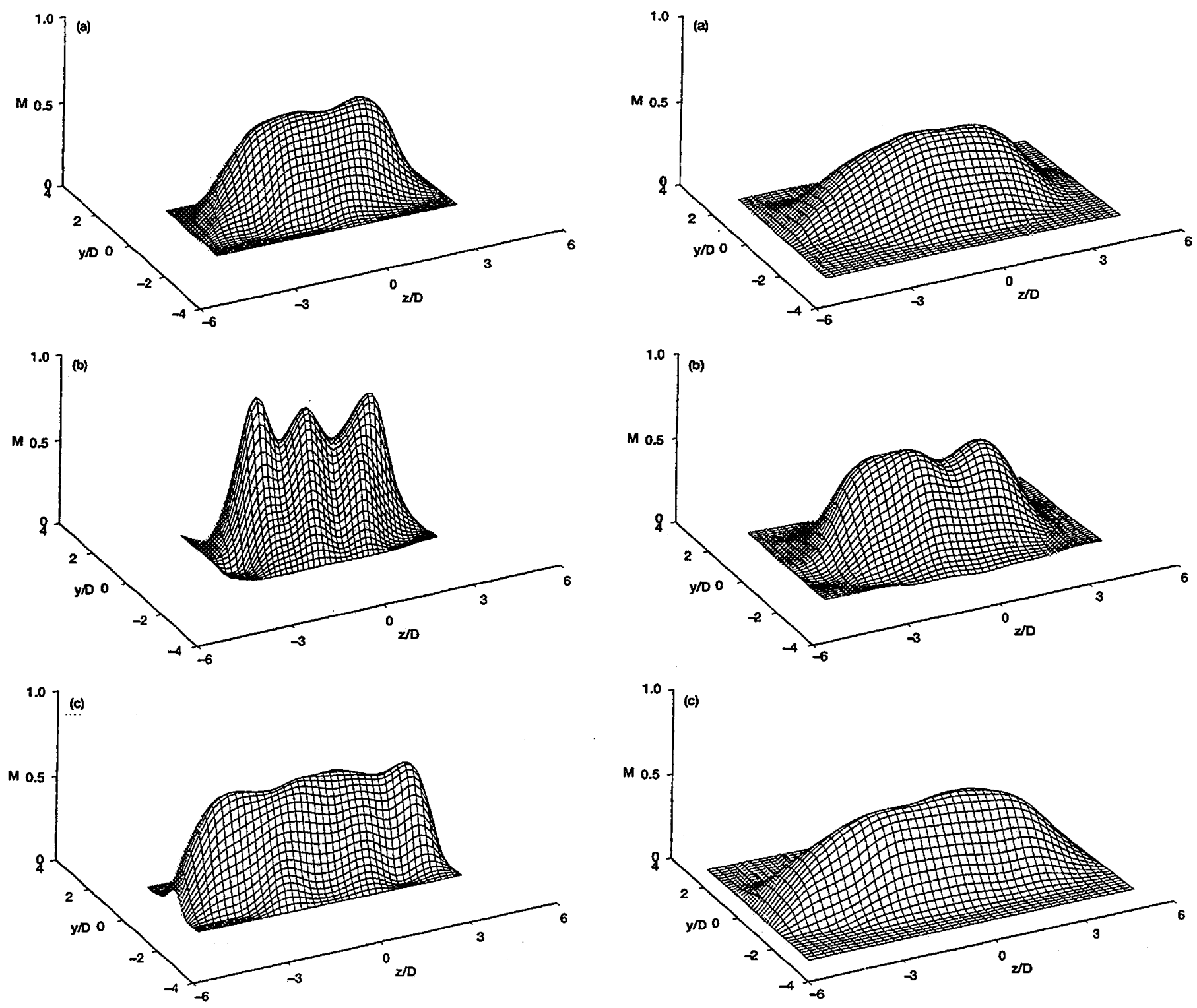

Figure 11. - Mean flowfield data at $x / D_{e}=7$ in the $Y Z$ plane. (a) $M_{j}=$ $1.4, s / h=5$; two out of four jets were synchronized. (b) $M_{i}=1.6$, $\mathrm{s} / \mathrm{h}=5$; none of the four jets were synchronized. (c) $M_{j}=1.6$, $s / h=8$; all four jets were synchronized.

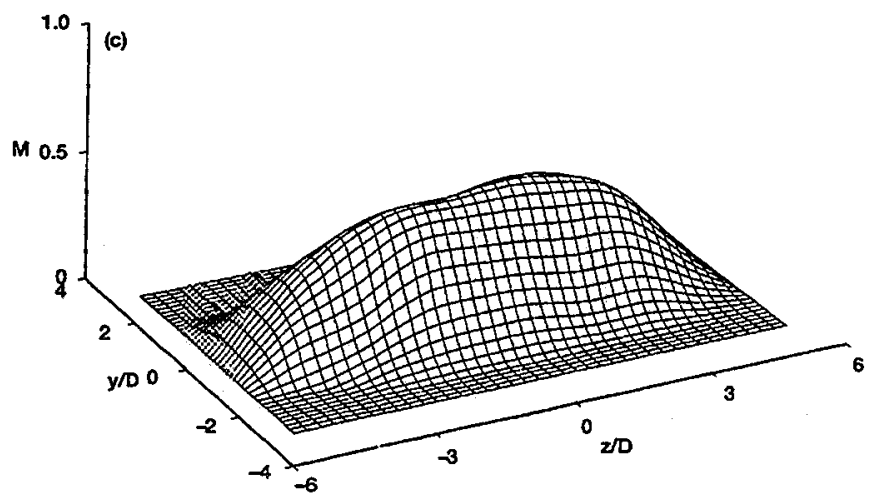

Figure 12.-Mean flowfield data at $x / D_{e}=12$ in the $Y Z$ plane. For $a$ description of parts (a), (b) and (c) see caption for Figure (11). 


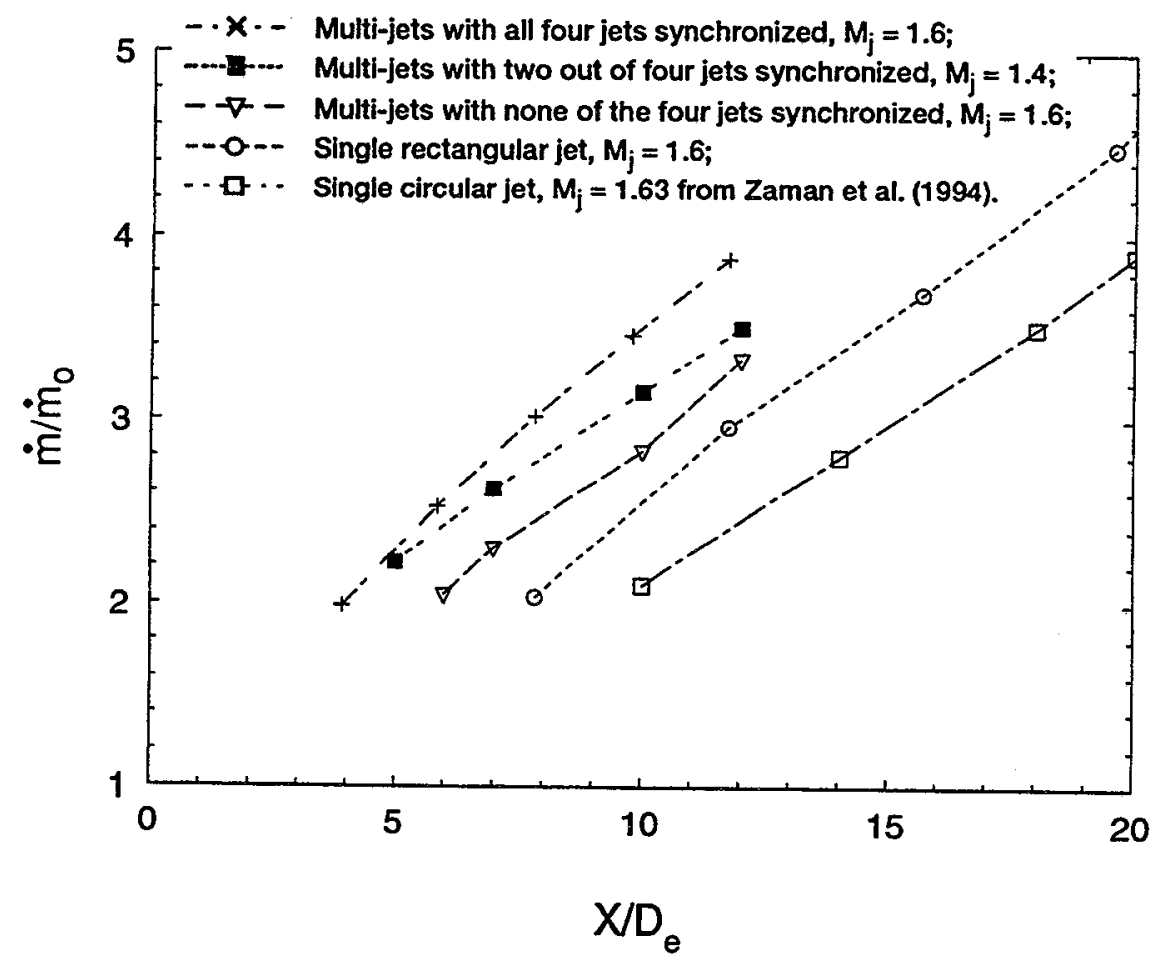

Figure 13.-Variation of the integrated mass-flux ratio with downstream distance.

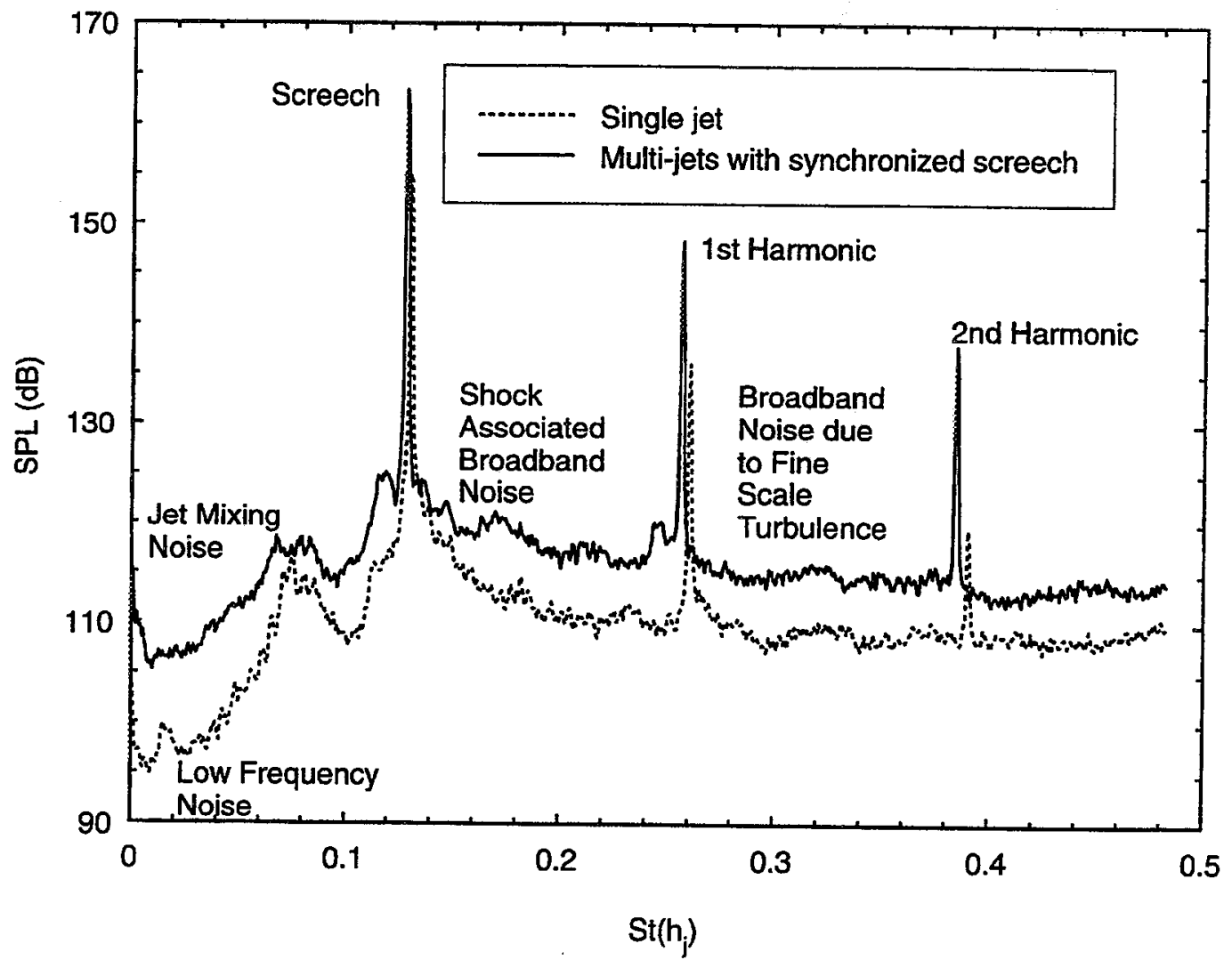

Figure 14.-Comparison of the sound pressure level spectra of single and multiple screech synchronized jets. 


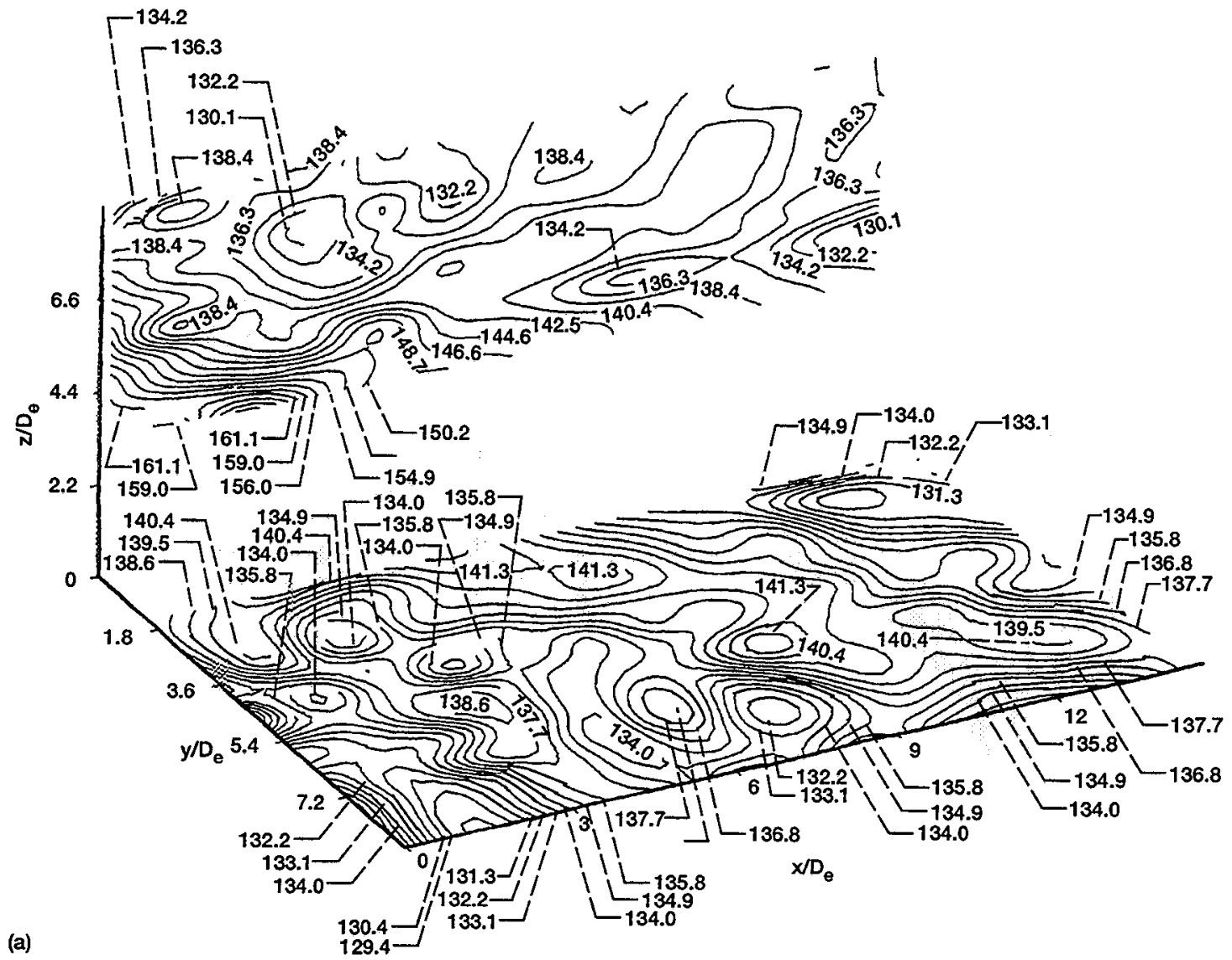

Figure 15.-Nearfield noise map of coherent sound pressure levels. (a) Sound pressure levels coherent at the screech frequency.

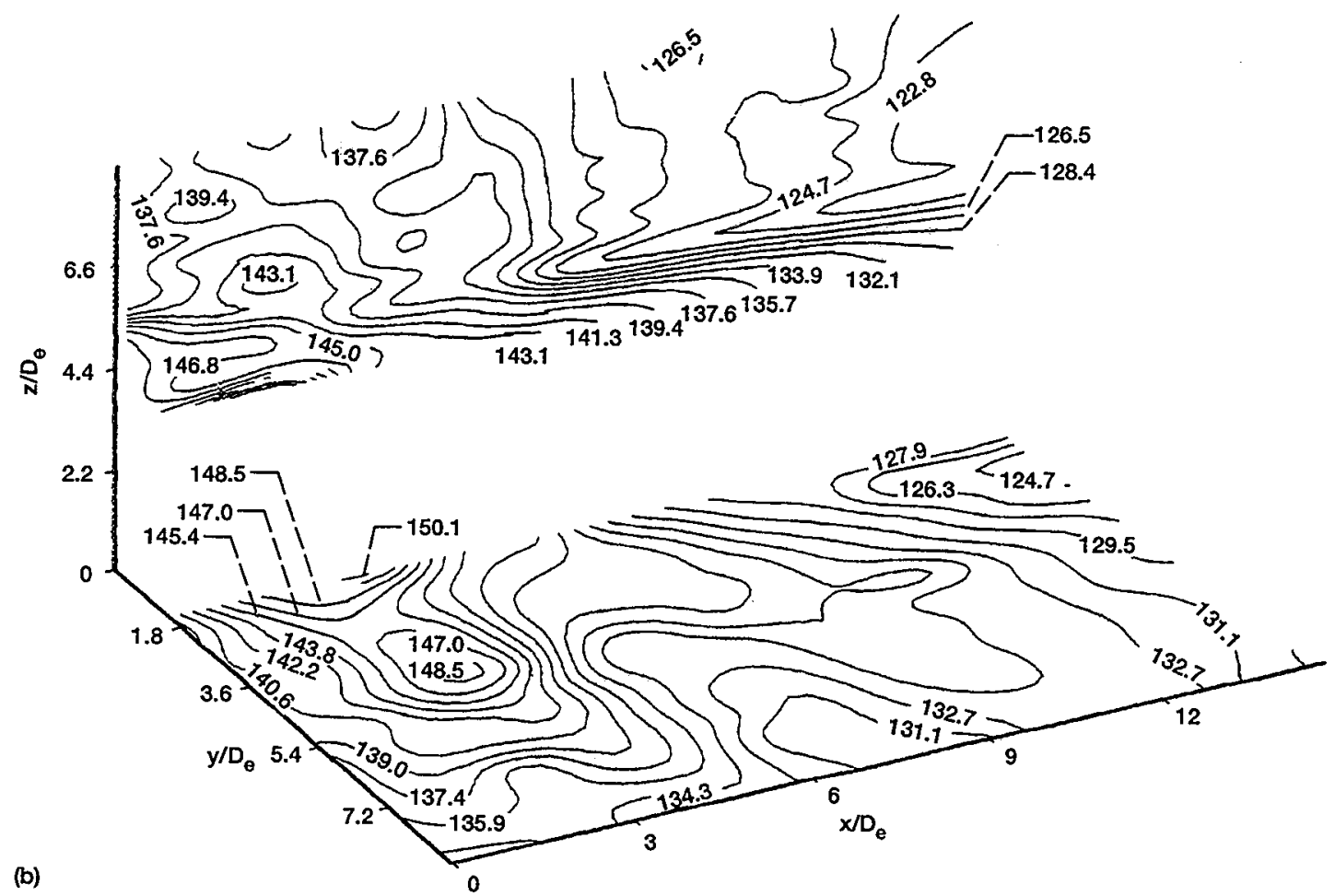

Figure 15.-Concluded. (b) Sound pressure levels coherent at the harmonic of the screech frequency. 

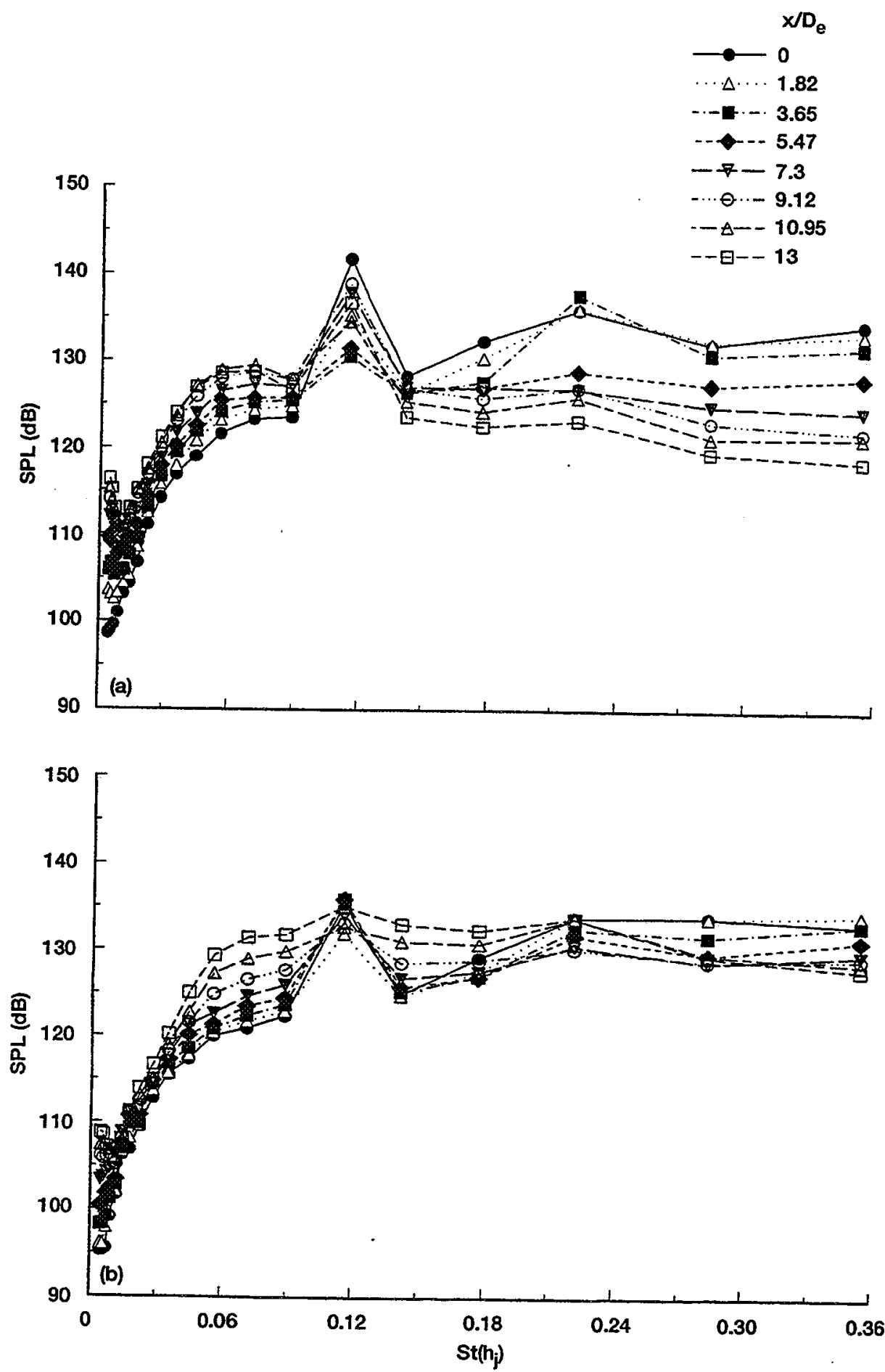

Figure 16. - Third-octave spectral evolution for multiple jets with synchronized screech. (a) Along $y / D_{e}=0, z / D_{e}=8.8$. (b) Along $z / D_{e}=0, y / D_{e}=8.8$. 

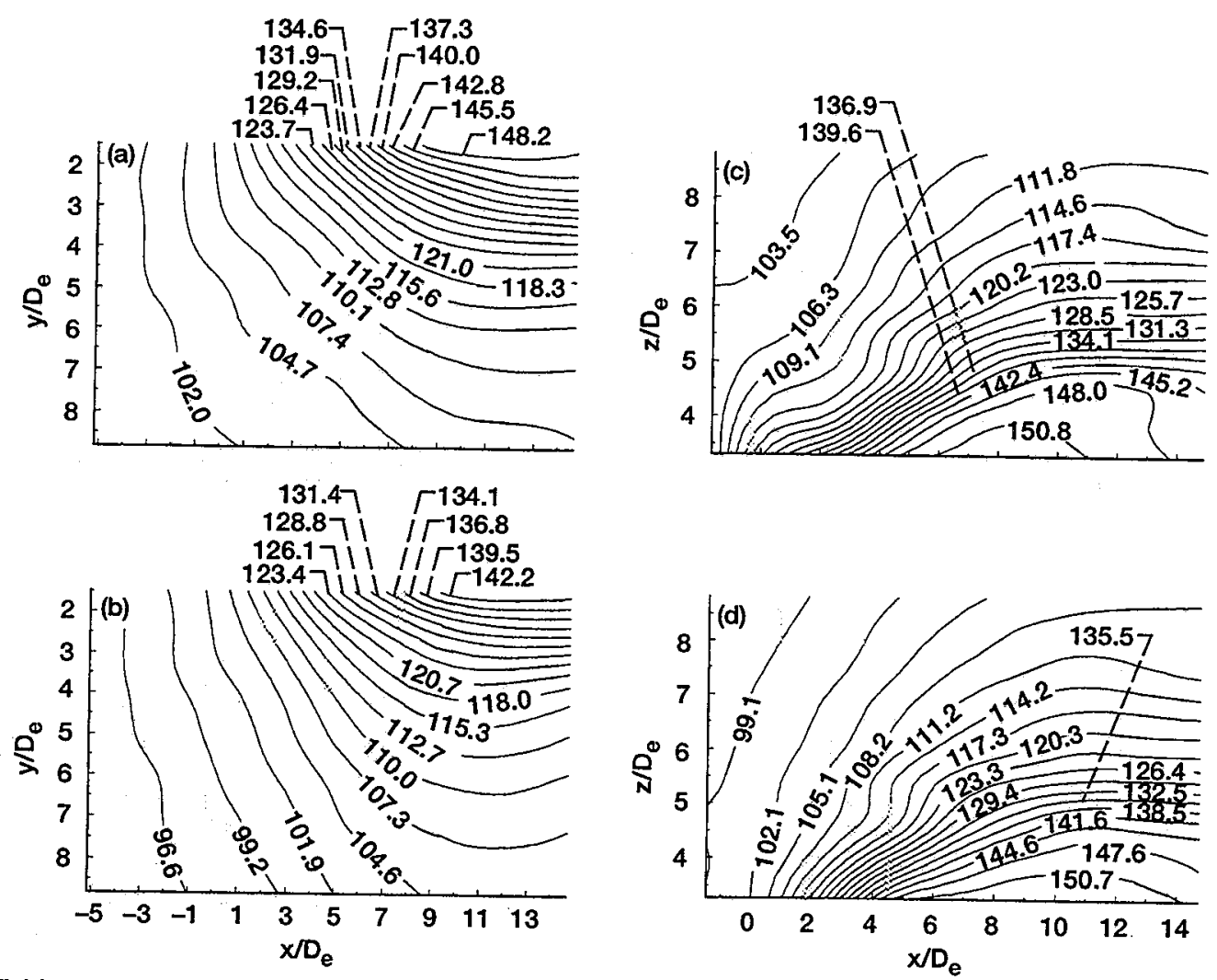

Figure 17. -Nearfield map of the low frequency noise; third-octave bin centered at $S t\left(h_{j}\right)=0.0118$ with lower and upperband limits of St $\left(h_{j}\right)=0.0133$ and 0.0167 respectively. (a) $X Y$ plane, $z / D_{e}=0$, multi-jets with synchronized screech. (b) $X Y$ plane, $z / D_{e}=0$, sum of four jets runindividually. (c) $X Z$ plane, $z / D_{e}=0$, multi-jets with synchronized screech. (d) $X Z$ plane, $z / D_{e}=0$, sum of four jets run individually.
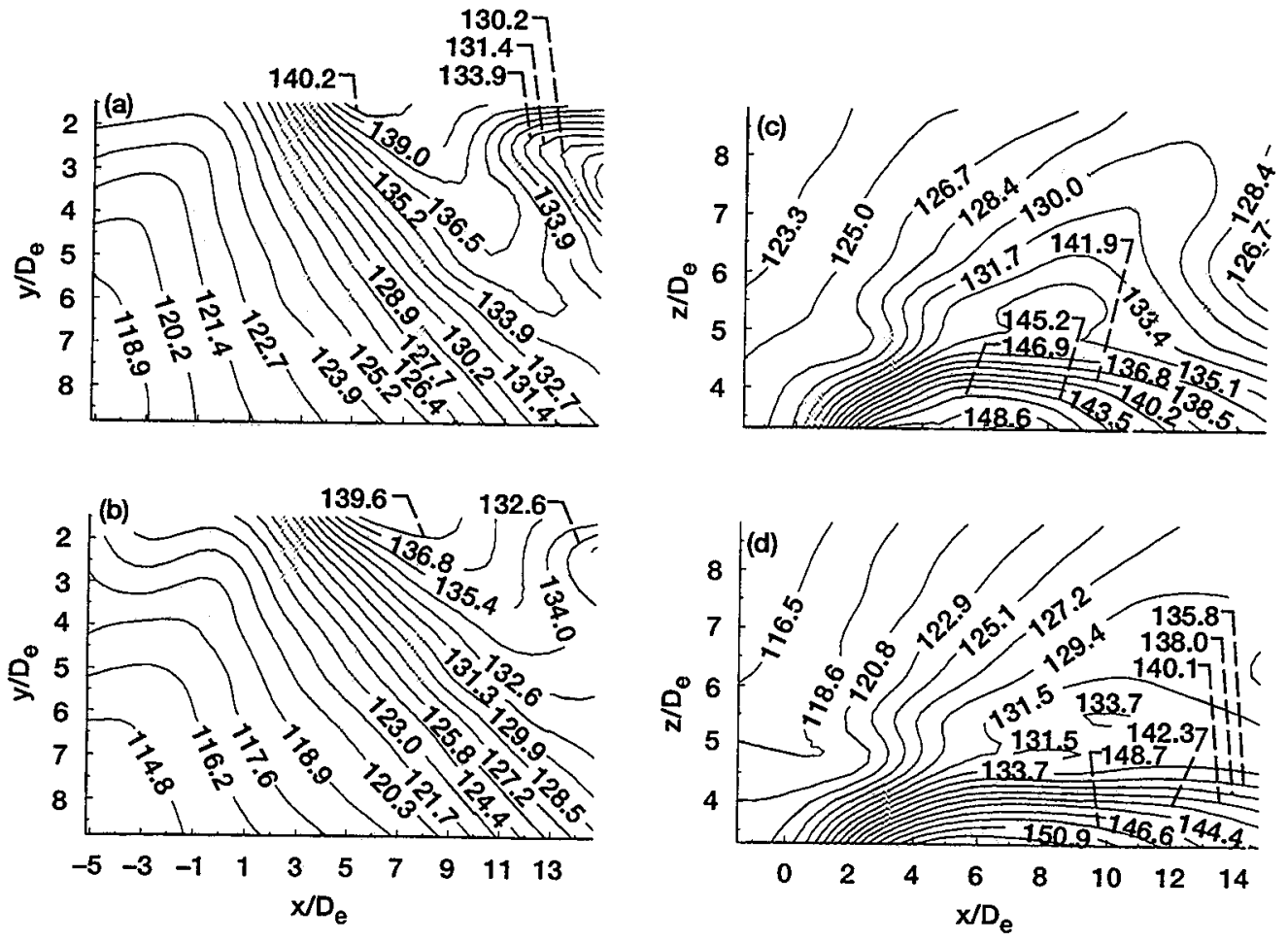

Figure 18.-Nearfield map of the jet mixing noise; third-octave bin centered at $\mathrm{St}\left(\mathrm{h}_{\mathrm{j}}\right)=0.075$ with lower and upperband limits of St $\left(h_{j}\right)=0.066$ and 0.084 respectively. For a description of parts $(a)-(d)$ see caption for Figure (17). 

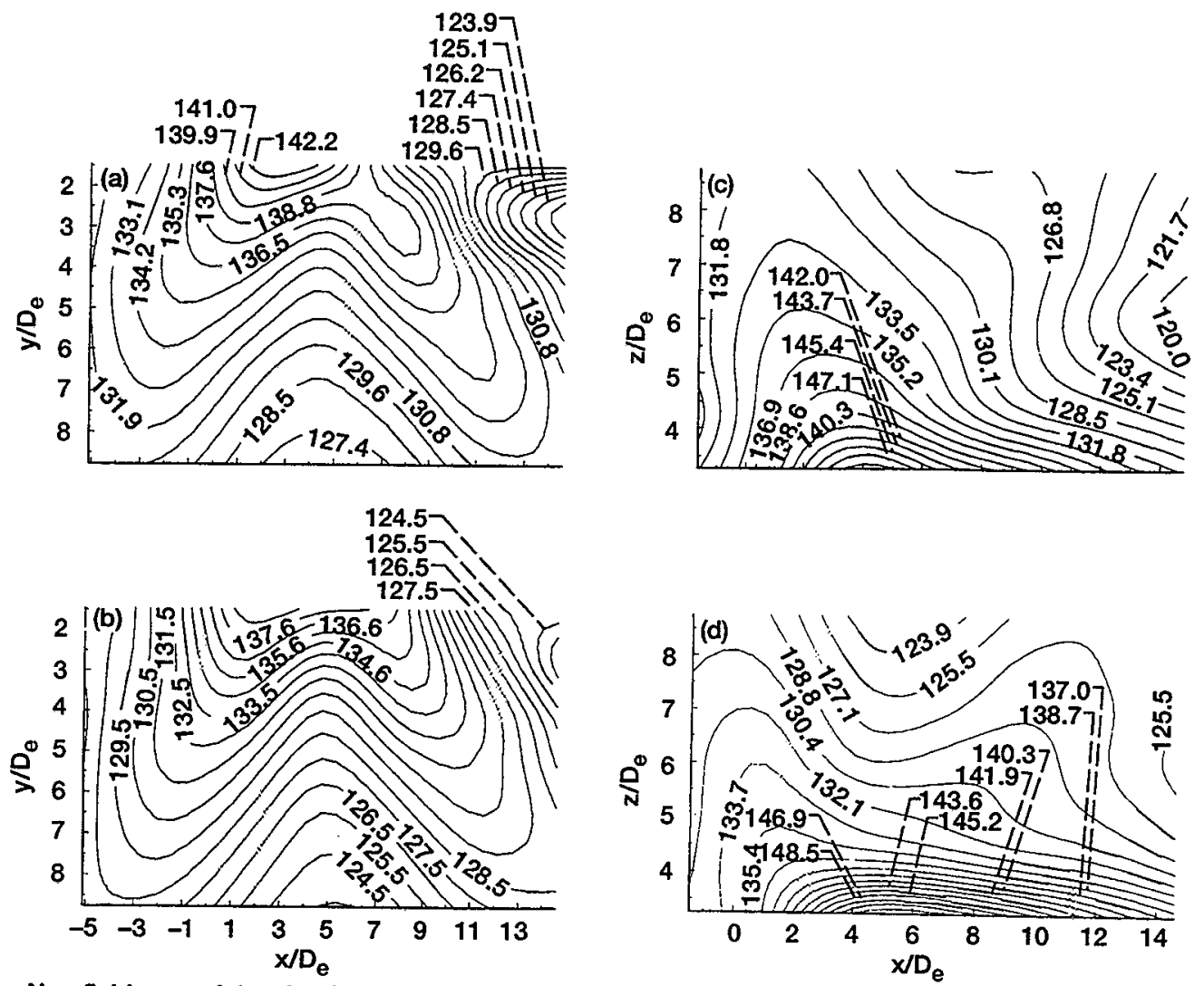

Figure 19. - Nearfield map of the shock-associated broadband noise; third-octave bin centered at St $\left(h_{j}\right)=0.189$ with lower and upperband limits of $S t\left(h_{j}\right)=0.168$ and 0.212 respectively. For a description of parts (a) - (d) see caption for Figure (17).
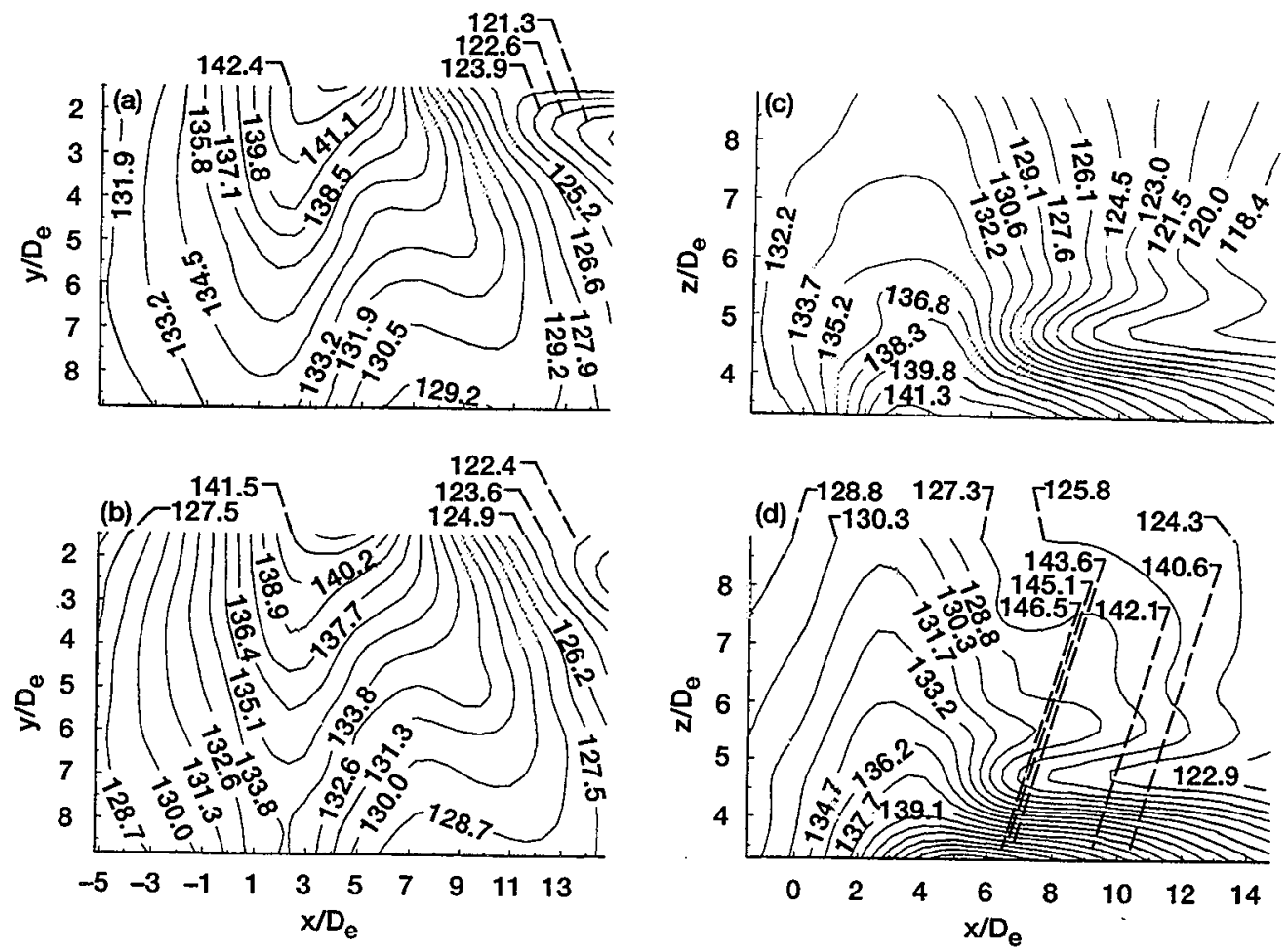

Figure 20.- Nearfield noise map of the high frequency broadband noise; third-octave bin centered at St $\left(h_{j}\right)=0.3024$ with lower and upperband limits of St $\left(h_{j}\right)=0.267$ and 0.336 respectively. For a description of parts (a) - (d) see caption for Figure (17). 

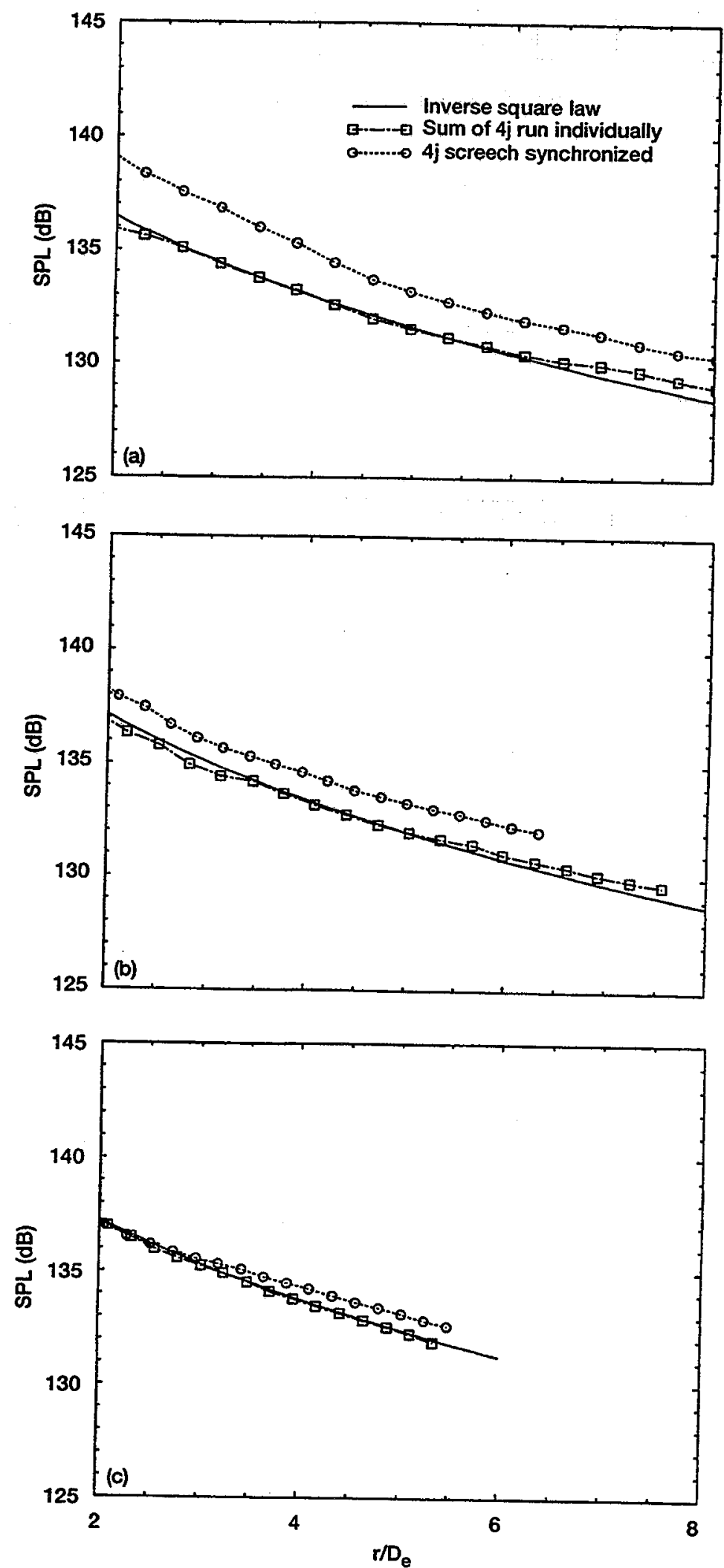

Figure 21.-Fall-off of the acoustic field along the direction of noise radiation. (a) Jet mixing noise. (b) Shock-associated broadband noise. (c) High frequency noise. 
Public reporting burden for this collection of information is estimated to average 1 hour per response. including the time for reviewing instructions, searching existing data sources, gathering and maintaining the data neoded, and completing and reviewing the collection of information. Send comments regarding this burden estimate or any other aspect of this coliection of information, including suggestions for reducing this burden, to Washington Headquanters Services, Directorate for Information Operations and Reports, 1215 Jefferson Davis Highway, Suite 1204, Arlington, VA 22202-4302, and to the Office of Management and Budget, Paperwork Reduction Project (0704-0188), Washington, DC 20503.
1. AGENCY USE ONLY (Leave blank)
2. REPORT DATE
November 1994
3. REPORT TYPE AND DATES COVERED
Final Contractor Report

\section{TITLE AND SUBTITLE}

Resonant Interaction of a Linear Array of Supersonic Rectangular Jets:

An Experimental Study

6. AUTHOR(S)

Ganesh Raman and Ray Taghavi

5. FUNDING NUMBERS

WU-537-02-22

C-NAS3-27186

7. PERFORMING ORGANIZATION NAME(S) AND ADDRESS(ES)

NYMA, Inc.

Engineering Services Division

2001 Aerospace Parkway

Brook Park, Ohio 44142

8. PERFORMING ORGANIZATION REPORT NUMBER

E-9128

9. SPONSORING/MONITORING AGENCY NAME(S) AND ADDRESS(ES)

10. SPONSORING/MONITORING AGENCY REPORT NUMBER

National Aeronautics and Space Administration

Lewis Research Center

Cleveland, Ohio 44135-3191

NASA CR-195398

11. SUPPLEMENTARY NOTES

Prepared for the 33rd Aerospace Sciences Meeting and Exhibit sponsored by the American Institute of Aeronautics and Astronautics, January 9-12,1994. Project manager, John M. Abbott, Internal Fluid Mechanics Division, NASA Lewis Research Center, organization code 2600, (216) 433-3607.

12a. DISTRIBUTION/AVAILABILITY STATEMENT

12b. DISTRIBUTION CODE

Unclassified - Unlimited

Subject Category 02

13. ABSTRACT (Maximum 200 words)

This paper examines a supersonic multi-jet interaction problem that we believe is likely to be important for mixing enhancement and noise reduction in supersonic mixer-ejector nozzles. We demonstrate that it is possible to synchronize the screech instability of four rectangular jets by precisely adjusting the inter-jet spacing. Our experimental data agrees with a theory that assumes that the phase-locking of adjacent jets occurs through a coupling at the jet lip. Although the synchronization does not change the frequency of the screech tone, its amplitude is augmented by $10 \mathrm{~dB}$. The synchronized multi-jets exhibit higher spreading than the unsynchronized jets, with the single jet spreading the least. We compare the nearfield noise of the four jets with synchronized screech to the noise of the sum of four jets operated individually. Our noise measurements reveal that the more rapid mixing of the synchronized multi-jets causes the peak jet noise source to move up stream and to radiate noise at larger angles to the flow direction. Based on our results, we believe that screech synchronization is advantageous for noise reduction internal to a mixer-ejector nozzle, since the noise can now be suppressed by a shorter acoustically lined ejector.

\section{SUBJECT TERMS}

Rectangular jet; Screech; Jet noise; Supersonic jet; Acoustics

17. SECURTYY CLASSIFICATION OF REPORT

Unclassified
18. SECURITY CLASSIFICATION OF THIS PAGE

Unclassified
19. SECURITY CLASSIFICATION OF ABSTRACT

Unclassified 